\author{
Universidade de São Paulo \\ Instituto de Física
}

\title{
Mapas Randômicos e \\ Espalhamento Caótico Não-Hiperbólico
}

Sabrina Camargo

Orientador: Prof. Dr. Celso Grebogi.

Dissertação apresentada ao Instituto de Física para obtenção do título de Mestre em Ciências.

Banca examinadora:

Prof. Dr. Celso Grebogi (USP)

Prof. Dr. Ricardo Luiz Viana (UFPR)

Prof. Dr. Sérgio Roberto Lopes (UFPR)

São Paulo

2005 
Sabrina Camargo

\section{Mapas Randômicos e \\ Espalhamento Caótico Não-Hiperbólico}

Dissertação apresentada ao Instituto de Física da Universidade de São Paulo para obtenção do título de Mestre em Ciências.

Área de concentração: Física.

Orientador: Prof. Celso Grebogi.

São Paulo

2005 
Aos meus avós, Mário e Aurita.

E aos meus pais, Nilton e Regina. 


\section{Agradecimentos}

À CAPES e ao Instituto de Física da USP pelo suporte.

Aos professores Pedro Salomão Santoro, pelos seminários, Alessandro Paulo Sérvio de Moura, pela preciosa ajuda na condução desse trabalho e especialmente ao professor Celso Grebogi, por me aceitar como aluna, pela orientação no mestrado e sobretudo pelo exemplo de cientista.

Aos novos amigos Michele Ferraz Figueiró, Julia Maria Ghiel, Rafael Ribeiro Dias Vilela de Oliveira, Jefferson Staffusa Elias Portela, Alessandro Alves da Silva e Viviane Poli.

Aos velhos amigos Thiago dos Santos Pereira, Ernani Anderson e Iris Antonio Maeda e às amigas Franciana Pedrochi, Iara Mantovani, Francielle Sato.

A Marcos César Danhoni Neves, que me deu a primeira oportunidade e ainda se tornou um grande amigo, digno da minha mais profunda admiração.

Aos meus pais, Nilton e Regina, à minha irmã Talita, aos meus avós e todos os meus tios, tias, primos e primas que sempre me apoiaram, me amaram e que principalmente, continuam confiando em mim.

Ao Kleto pelo apoio incondicional, pela compreensão e pelo amor. 
Se as coisas são inatingíveis... ora! Não é motivo para não querê-las... Que tristes os caminhos se não fora A mágica presença das estrelas! Mário Quintana 


\section{Resumo}

Num problema de espalhamento temos partículas incidentes sobre uma região de espalhamento que, depois de interagir por algum tempo nessa região, escapam para o infinito. Quando o espalhamento é caótico, a função de espalhamento (que é a relação entre uma variável antes do espalhamento e outra variável depois do espalhamento), apresenta singularidades sobre um conjunto de Cantor de condições iniciais. O espalhamento caótico pode ser dividido em dois tipos: espalhamento não-hiperbólico e hiperbólico. No espalhamento não-hiperbólico, o conjunto invariante contém órbitas estáveis. O decaimento das partículas que escapam do conjunto invariante é regido por uma lei de potência com relação ao tempo. No caso do espalhamento hiperbólico, a sela caótica é hiperbólica e todas as órbitas que a compõem são instáveis. O decaimento das partículas na região de espalhamento segue uma exponencial decrescente. Investigamos a transição do espalhamento não-hiperbólico para o hiperbólico quando ruído é adicionado à dinâmica do sistema. Isto porque prevíamos que o ruído reduzisse o efeito de aprisionamento (stickness) dos conjuntos de órbitas estáveis, provocando um decaimento exponencial. Introduzimos perturbações randômicas a fim de simular flutuações reais que ocorrem em sistemas físicos, como por exemplo, um vórtex que depende irregularmente do tempo no estudo de fluidos. Assim, usamos o conceito de mapas randômicos, que são mapas onde um ou mais parâmetros são variados aleatoriamente a cada iteração. Estudamos então, os efeitos provocados por perturbações randômicas em um sistema com espalhamento caótico não-hiperbólico. 


\section{Abstract}

In a scattering problem we have particles inciding on a scattering region and these particles, after spending some time in this region, escape towards infinity. When the scattering is chaotic, the scattering function (a function that relates an input variable with an output variable), is singular on a Cantor set of initial conditions. The chaotic scattering can be either non-hyperbolic or hyperbolic. In the non-hyperbolic scattering, the invariant set has stable orbits. This decay is governed by a power law in time. In the hyperbolic case, the chaotic saddle is hyperbolic and all the orbits are unstable. The decay of the particles is a decreasing exponential in the time. We investigate the transition from non-hyperbolic to hyperbolic scattering as noise is added to the system. One expects that noise will reduce the stickness of the regular regions, resulting in an exponential decay law, typical of hyperbolic systems. We apply random perturbations in order to simulate the real fluctuations that occur in physical systems, for example, an aperiodic vortex in a fluid flow. So, we work with random maps, where we change randomly one or more parameters on each iteration. We study thus, the effects of the random perturbations on a system having non-hyperbolic scattering. 


\section{Sumário}

$\begin{array}{lll}\text { Resumo } & \mathbf{v}\end{array}$

Abstract

1 Introdução 1

2 Mapas Randômicos 4

2.1 Mapa de Hénon . . . . . . . . . . . . . . . . . . . 5

2.2 Mapa de Ikeda . . . . . . . . . . . . . . . . . . . . . . . . 8

2.3 Mapa de Zaslavsky . . . . . . . . . . . . . . . . . . . . . . . 9

3 Espalhamento Caótico $\quad 13$

3.1 Dimensão Fractal . . . . . . . . . . . . . . . . . . . . . . . . . . 16

3.2 Sela Caótica . . . . . . . . . . . . . . . . . . . . 21

3.3 Transição para o Caos . . . . . . . . . . . . . . . . . . . 21

4 Espalhamento Não-Hiperbólico $\quad 32$

4.1 Espalhamento Caótico Não-Hiperbólico com Perturbações Randômicas . . . . . . . . . . . . . . . . . . . 39

4.1.1 Tempo de Decaimento . . . . . . . . . . . . . . 40

5 Discussão 46

Referências Bibliográficas $\quad 49$ 


\section{Capítulo 1}

\section{Introdução}

O fenômeno do caos consiste na extrema sensibilidade da dinâmica às condições iniciais. Originalmente, o caos foi investigado e definido em sistemas confinados, nos quais as trajetórias estão restritas a um volume finito do espaço de fase. Mais tarde, percebeu-se que o caos também pode estar presente em sistemas abertos, nos quais as trajetórias não são confinadas. O caso típico é o do espalhamento, em que partículas vindas do infinito incidem sobre uma região de interação de extensão finita, e depois de um transiente escapam para o infinito novamente.

O espalhamento caótico é uma manifestação física do caos transiente, devido à existência de conjuntos caóticos invariantes não-atratores, isto é, as selas caóticas no espaço de fase. Dentre os resultados produzidos por esses conjuntos invariantes, um conjunto de Cantor de singularidades surge em funções de espalhamento mensuráveis fisicamente, relacionando uma variável de saída da região de espalhamento com uma variável de entrada [1]. Em sistemas com espalhamento caótico, o estado final do espalhamento depende de maneira sensível das condições iniciais [2]. Se um sistema apresenta espalhamento caótico, qualquer função de espalhamento, relacionando o estado final com o estado inicial do sistema (por exemplo, o ângulo de espalhamento como função do parâmetro de impacto), tem uma estrutura fractal complexa, com um conjunto de Cantor de singularidades.

A dinâmica do espalhamento caótico é dominada por um conjunto invariante composto por órbitas confinadas à região de interação, e que nunca escapam, tanto para $t \rightarrow+\infty$ como para $t \rightarrow-\infty$. Este conjunto de órbitas é conhecido como sela caótica. Se o espalhamento for caótico, o conjunto invariante tem uma estrutura fractal no espaço de fase, que causa a sensibilidade às condições iniciais da dinâmica transiente [3]. A estrutura fractal das funções de espalhamento que mencionamos acima é um reflexo direto da estrutura fractal do conjunto invariante de órbitas. Com efeito, as singularidades correspondem a condições iniciais contidas na variedade estável de uma das órbitas do conjunto invariante. 
O espalhamento caótico pode ser dividido em dois tipos: espalhamento hiperbólico e não-hiperbólico. Em ambos os casos, a cada iteração uma fração das partículas que incidiram sobre a região de espalhamento escapam para o infinito. Esse decaimento das partículas é regido por leis distintas em cada caso. No caso do espalhamento hiperbólico, a sela caótica é hiperbólica e todas as órbitas que a compõem são instáveis. O decaimento das partículas na região de espalhamento segue uma exponencial decrescente. No espalhamento não-hiperbólico, o conjunto invariante contém órbitas estáveis e o decaimento das partículas é regido por uma lei de potência com relação ao tempo. Uma outra diferença importante ocorre na dimensão fractal $d$ da sela caótica [4]. Em sistemas não-hiperbólicos, $d$ assume o valor máximo $d=D_{e f}$, onde $D_{e f}$ é a dimensão do espaço de fase em que a dinâmica acontece. Em sistemas hiperbólicos, temos sempre $d<D_{e f}$.

De forma a considerar as flutuações sofridas pelos parâmetros que definem um sistema real, que não são incluídas no modelo determinístico, supomos que elas são estocásticas e usamos o conceito de mapas randômicos [5]. Os mapas randômicos são mapas onde um ou mais parâmetros são variados aleatoriamente a cada iteração, de acordo com uma certa distribuição. Esta idéia foi aplicada tanto em sistemas dissipativos com atratores [5] como em sistemas com espalhamento [6,7], com a dinâmica sendo hiperbólica em ambos os casos. Um dos resultados mais importantes é que a estrutura fractal dos conjuntos invariantes é mantida (snapshot attractors, snapshot saddles), mesmo nesta dinâmica nãodeterminística. Em particular, a dimensão fractal e outros "invariantes" têm valores bem definidos, apesar da estrutura dos conjuntos invariantes mudarem erraticamente no tempo.

Neste trabalho, estudamos mapas randômicos em sistemas não-hiperbólicos, especialmente em sistemas Hamiltonianos com espalhamento. O mapa em estudo é resultado de uma transformação do mapa de Hénon e apresenta tanto o comportamento hiperbólico quanto o comportamento não-hiperbólico, dependendo dos valores do parâmetro. Estudamos as características mais importantes do espalhamento não-hiperbólico e em seguida observamos quais mudanças foram acarretadas pela introdução da randomicidade no parâmetro. Porém, para que isso fosse feito estudamos antes algumas propriedades de mapas randômicos e problemas de espalhamento hiperbólico.

Seguindo o trabalho de Romeiras et al. [5], o Cap. 2 traz alguns exemplos de mapas com parâmetros randômicos. Reproduzimos alguns dos resultados de Romeiras et al. [5] para os mapas de Hénon e de Ikeda e também o cálculo da dimensão fractal feito por Namenson et al. [6] para um atrator instantâneo, resultante da versão randômica do mapa de Zaslavsky e obtivemos um valor ligeiramente diferente para a dimensão do atrator, provavelmente por diferenças na precisão dos cálculos.

O Cap. 3 apresenta um estudo baseado principalmente em dois trabalhos. O primeiro, de 
Bleher et al. [2], trata de um caso de espalhamento provocado por um potencial simétrico, onde existe uma transição abrupta do espalhamento regular para o espalhamento caótico, de acordo com os valores da energia. Assim como no Cap. 2, reproduzimos alguns resultados, como a função de espalhamento, o cálculo numérico da dimensão fractal, os gráficos das variedades estável e instável, a sela caótica, entre outros. O segundo trabalho em que baseamos o Cap. 3 é de Ding et al. [8], que trata da evolução de um sistema com espalhamento regular para o espalhamento caótico. Essa transição se dá por meio de uma sequiência de eventos que se inicia com uma bifurcação sela-centro, seguida por uma bifurcação de duplicação de período e de interseções homoclínicas e heteroclínicas. No fim do capítulo temos uma analogia com a ferradura de Smale.

O Cap. 4 constitui a essência de nosso trabalho, onde apresentamos os resultados do nosso estudo de sistemas com espalhamento caótico não-hiperbólico sob perturbações randômicas. Iniciamos com a construção de um conjunto de Cantor de dimensão igual a 1. Então estudamos o caso de espalhamento caótico não-hiperbólico utilizando o mapa apresentado por Lau et al. [4], sendo esse mapa não-hiperbólico para alguns valores do parâmetro e hiperbólico para outros. Para o caso não-hiperbólico, nós calculamos a função de espalhamento e o gráfico da variedade estável; calculamos a dimensão fractal do conjunto para um valor do parâmetro e construímos o gráfico do decaimento das partículas na região de espalhamento. Estabelecidas as características do espalhamento caótico não-hiperbólico, aplicamos uma perturbação randômica no parâmetro e observamos seus efeitos na função de espalhamento, no conjunto análogo à variedade estável e no tempo de decaimento.

Encerramos esse trabalho no Cap. 5, onde discutimos os resultados do Cap. 4 e suas possíveis razões, como também apresentamos perspectivas para a continuação desse estudo. 


\section{Capítulo 2}

\section{Mapas Randômicos}

No estudo dos problemas de espalhamento caótico, a randomicidade entra com o objetivo de incluir as flutuações sofridas por sistemas reais que não são consideradas no modelo determinístico.

Neste capítulo seguiremos o trabalho de Romeiras et al. [5], com a aplicação de perturbações randômicas aos mapas de Hénon e Ikeda, e o mapa randômico de Zaslavski, uma aplicação randômica em problemas de escoamento de fluidos.

Em um mapa randômico os parâmetros variam randomicamente a cada iteração, de acordo com uma distribuição de probabilidade. O problema do efeito da randomicidade em atratores estranhos pode ser abordado de duas formas: na primeira, temos uma nuvem de condições iniciais que é iterada para frente no tempo sob uma dinâmica com ruído; enquanto na segunda abordagem, consideramos uma única condição inicial e plotamos sua posição no espaço de fase sob uma dinâmica randômica para $t$ tempos. Na ausência de randomicidade as duas maneiras são equivalentes, porém quando consideramos um sistema dinâmico randômico a situação torna-se diferente. Quando tomamos uma única condição inicial, o resultado é uma versão "granulada" do atrator estranho que existe na ausência de randomicidade. Entretanto, quando tomamos uma nuvem de condições iniciais o resultado é tipicamente uma medida fractal. Este resultado é chamado de snapshot attractor, isto é, o resultado de muitas iterações de uma nuvem de condições iniciais vista num único instante de tempo, daí o nome snapshot attractor, no sentido de um "instantâneo" do atrator. Esses snapshots fornecem uma "fotografia" dos atratores, mostrando as semelhanças com os atratores de parâmetros fixos, inclusive uma estrutura do tipo Cantor. O espectro de dimensões do atrator instantâneo independe do tempo, embora as características do atrator dependerem do instante de tempo em que o atrator é visto.

Nas duas seções que se seguem comparamos os atratores de $N$ condições iniciais na bacia de atração dos atratores de Hénon [9] e Ikeda [10,11]. Iteramos cada condição inicial 
$n$ vezes e plotamos a última posição de todas elas, a fim de obter os "instantâneos" dos atratores de Hénon e Ikeda.

\subsection{Mapa de Hénon}

Em 1976, Hénon apresentou o que ele chamou de um modelo mais simples para o sistema que Lorenz havia proposto em 1963. Na construção de seu modelo, Hénon seguiu três passos: o primeiro foi não considerar todas as trajetórias no espaço de fase tridimensional, mas somente as interseções com uma superfície bidimensional, usando o método das seções de Poincaré. O segundo e mais importante passo foi abandonar o sistema de equações diferenciais e definir um mapa de equações algébricas. Apesar deste novo mapa não corresponder ao sistema de Lorenz, ele mantém suas características. A terceira e última etapa foi determinar o mapa que hoje leva o nome de Hénon [9],

$$
\begin{aligned}
& x_{i+1}=1-a x_{i}^{2}+y_{i}, \\
& y_{i+1}=b x_{i} .
\end{aligned}
$$

(a)

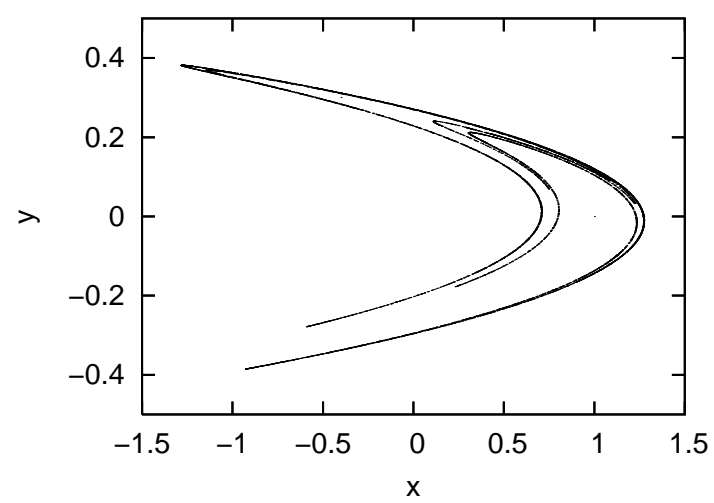

(b)

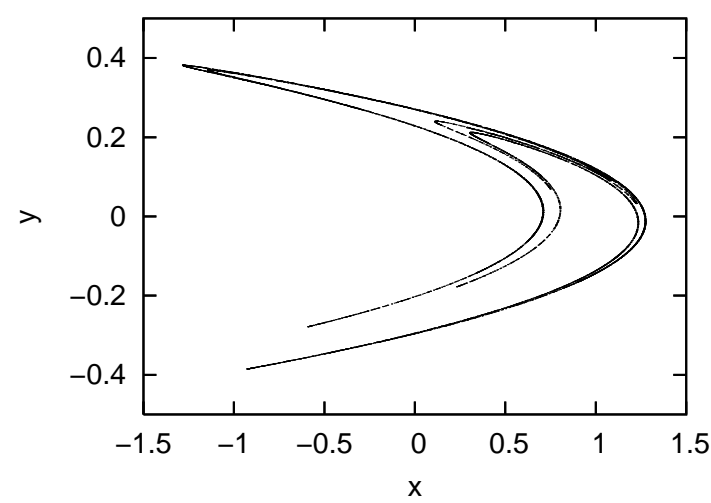

Figura 2.1: Como no artigo original, temos o mapa de Hénon calculado para duas condições iniciais distintas. Com $a=1,4$ e $b=0,3$, foram feitas $10^{4}$ iterações para $x_{0}=0$ e $y_{0}=0 \mathrm{em}$ (a); em (b), $x_{0}=0,63135448$ e $y_{0}=0,18940634$. Como as duas figuras são similares, o que vemos é essencialmente $\mathrm{o}$ atrator.

Modificando as Eqs. (2.1) podemos escrever o mapa como:

$$
\begin{aligned}
& x_{i+1}=a_{i}-x_{i}^{2}+b_{i} y_{i}, \\
& y_{i+1}=x_{i} .
\end{aligned}
$$


A versão randômica desse mapa é dada quando os parâmetros $a_{i}$ e $b_{i}$ variam a cada iteração, da seguinte forma:

$$
\begin{aligned}
& a_{i}=\bar{a}+\Delta_{a} r_{i}, \\
& b_{i}=\bar{b}+\Delta_{b} r_{i} .
\end{aligned}
$$

(a)

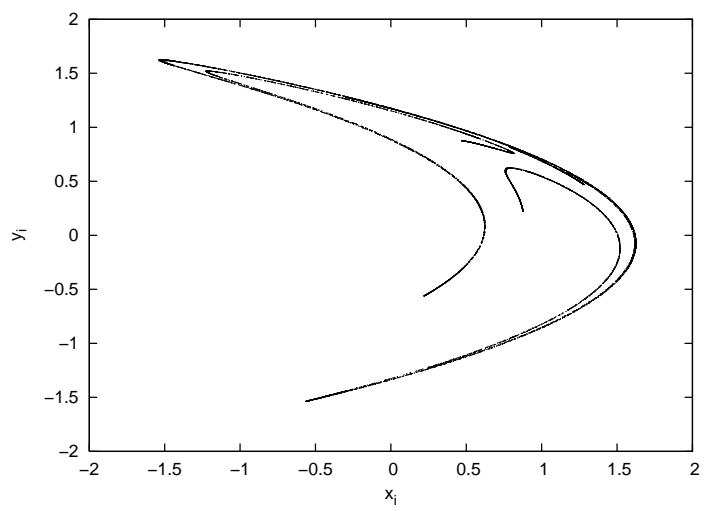

(c)

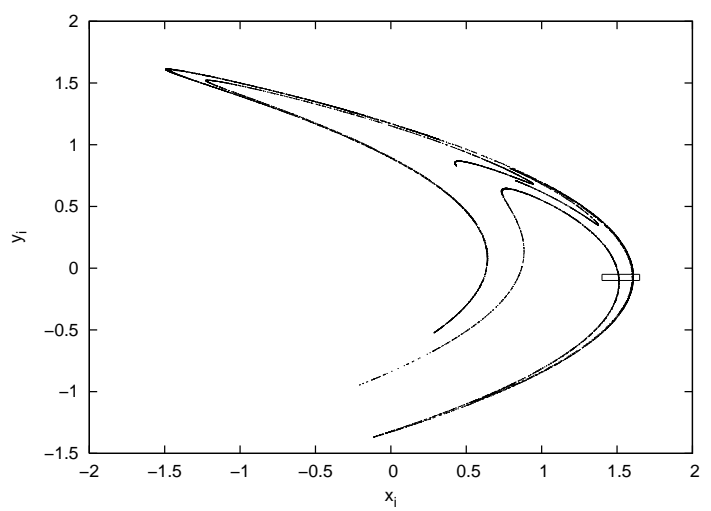

(b)

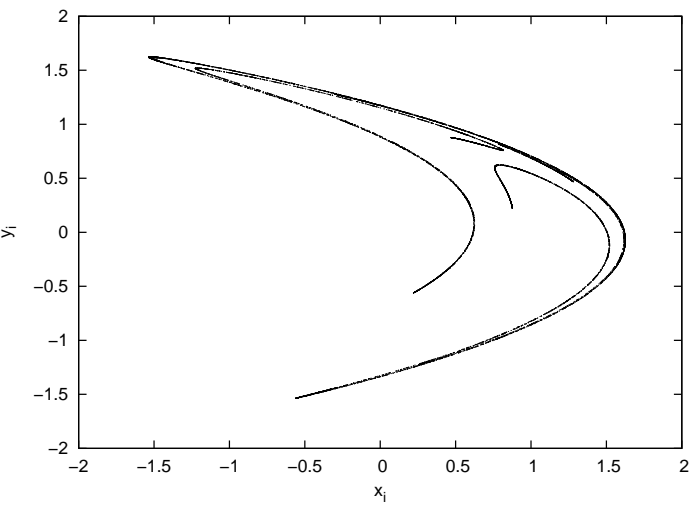

(d)

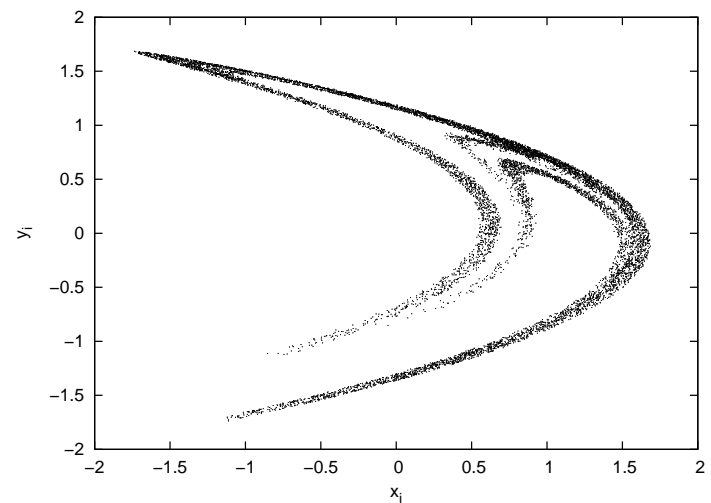

Figura 2.2: As Figs. (a) e (b) mostram que na ausência de randomicidade o resultado da iteração de $10^{4}$ condições iniciais vistas num único instante de tempo é equivalente ao gráfico da posição de uma condição inicial plotada para $t$ tempos. Quando introduzimos um fator randômico, esses dois procedimentos se distinguem: em (c) o atrator instantâneo mantém as características do atrator não perturbado, enquanto (d) apresenta uma versão "granulada" do atrator não perturbado. A região destacada em (c) está ampliada na Fig. 2.3.

Os parâmetros $\bar{a}, \Delta_{a}, \bar{b}$ e $\Delta_{b}$ são fixos e $r_{i}$ é uma variável randômica descorrelacionada, com distribuição de probabilidade uniforme no intervalo $[-1,1]$. Para a Fig. 2.2(a) plotamos o espaço de fase de $10^{4}$ condições iniciais distribuídas uniformemente em $-1<x<1$ e $-1<y<1$, na iteração $t=250$, com um transiente de 100 iterações e com os seguintes parâmetros: $\bar{a}=1,15, \bar{b}=0,4$ e $\Delta_{a}=\Delta_{b}=0$. Neste caso, não estamos perturbando os parâmetros do mapa, pois fixando $\Delta_{a}=\Delta_{b}=0$ mantemos os parâmetros $a_{i}$ e $b_{i}$ cons- 
(a)

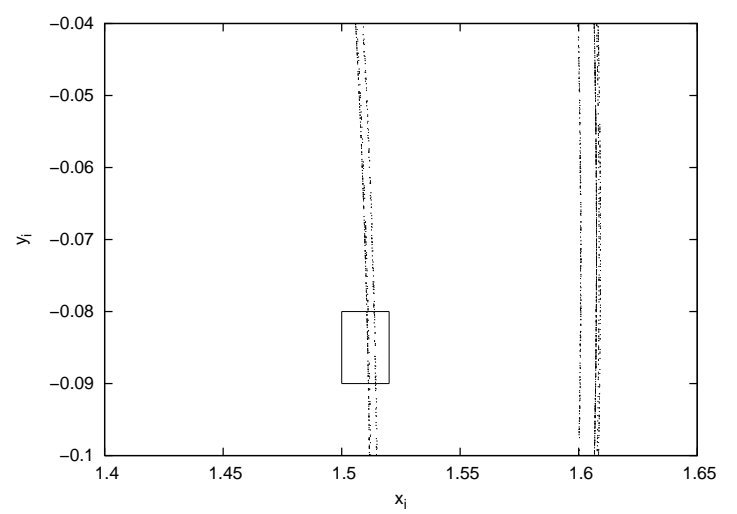

(b)

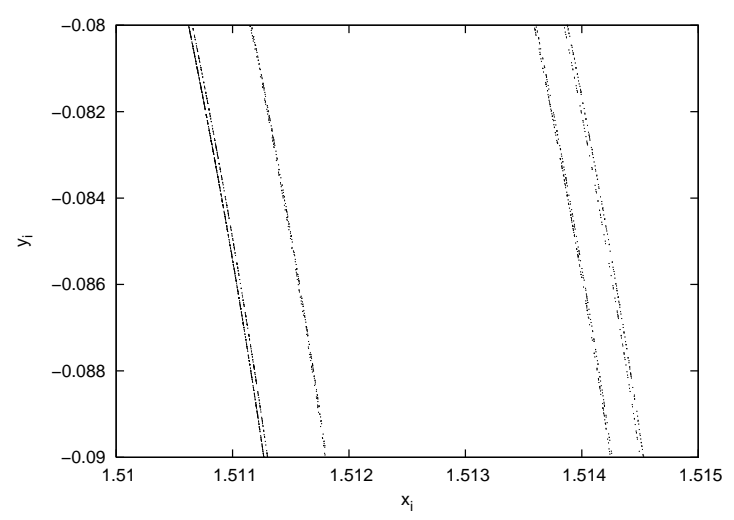

Figura 2.3: Em (a) temos a ampliação da Fig. 2.2 (c). O atrator instantâneo mantém a estrutura tipo Cantor característica do atrator não perturbado. Em (b) temos uma ampliação de (a). Usamos $2 \times 10^{5}$ condições iniciais em (a) e $4 \times 10^{6} \mathrm{em}(\mathrm{b})$.

tantes. Dessa forma, o aspecto geral de $10^{4}$ condições iniciais vistas no tempo $t=250$ é o mesmo de $10^{4}$ iterações de uma única condição inicial plotadas para todos os tempos. Na Fig. 2.2(b) temos $10^{4}$ iterações da condição inicial escolhida aleatoriamente, usando os mesmos parâmetros da Fig. 2.2(a). Porém quando tomamos $\Delta_{a}=0$ e $\Delta_{b}=0,05$, o resultado de $10^{4}$ condições iniciais vistas num tempo $t$ é diferente do resultado de $10^{4}$ iterações de uma condição inicial plotadas para todos os tempos, como mostram as Figs. 2.2 (c) e (d). Usamos as mesmas condições iniciais da Fig. 2.2(a) para Fig. 2.2(c) e a mesma condição inicial da Fig. 2.2(b) para Fig. 2.2(d). Podemos ver que a Fig. 2.2(c) mantém as principais características do atrator de parâmetros fixos, ao passo em que na Fig. 2.2(d) temos uma versão "granulada" do atrator original. Na Fig. 2.3 mostramos ampliações da região em destaque na Fig. 2.2 (c), quando obtivemos um atrator instantâneo. Das ampliações de 2.2 (c) temos, qualitativamente, que as características fractais do atrator de Hénon são preservadas, pois encontramos a estrutura tipo Cantor em sucessivas ampliações. Para a Fig. 2.3 (a) utilizamos $2 \times 10^{5}$ condições iniciais e para a Fig. 2.3 (b) foram utilizadas $4 \times 10^{6}$. 


\subsection{Mapa de Ikeda}

Em 1979, Ikeda apresentou um modelo para um sistema de laser em que a luz transmitida por uma cavidade circular contendo um meio dielétrico não-linear passa de um estado estacionário periódico para estados não-periódicos quando a intensidade da luz incidente aumenta [10]. O estado não-periódico é caracterizado por uma variação caótica da intensidade da luz.

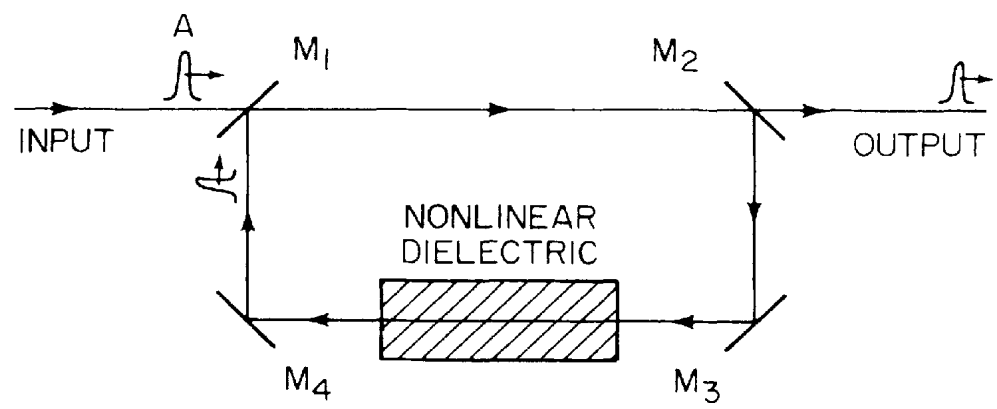

Figura 2.4: Esquema ilustrativo da cavidade modelada pelo mapa de Ikeda. (Grebogi et al. [12]). Input é o sinal de entrada e output é o sinal de saída. O sinal de entrada é parcialmente trasmitido pelos espelhos $M_{i}, i=1,2,3,4$, incidindo sobre um meio dielétrico não-linear (nonlinear dielectric).

O mapa de Ikeda é dado por,

$$
z_{i+1}=a+b z_{i} \exp \left[i\left(k-\frac{p}{\left(1+\left|z_{i}\right|^{2}\right)}\right)\right],
$$

onde $z_{i}$ é complexo ( $x_{i}$ é a parte real e $y_{i}$ a parte imaginária de $z_{i}$ ) e $a$ é a amplitude de uma seqüência de pulsos luminosos passando por um espelho parcialmente trasmissor $M_{1}$. $\mathrm{O}$ intervalo de tempo entre os pulsos é ajustado ao tempo de uma volta no sistema. A amplitude e o ângulo de fase do $i$-ésimo pulso ao alcançar o lado direito do espelho $M_{1}$ são $\left|z_{i}\right|$ e $z_{i}$, respectivamente. Na Eq. (2.3), os termos possuem os seguintes significados: $(1-b)$ fornece a fração de energia em um pulso transmitido ou absorvido nas quatro reflexões de $M_{1}, M_{2}, M_{3}$, e $M_{4}$ (note que o termo presente na Eq. (2.3) é $b$ ); $k$ é a diferença de fase que o pulso sofrerá na ausência do meio não-linear; e o termo $-p /\left(1+\left|z_{i}\right|^{2}\right)$ é a diferença de fase em decorrência do meio não-linear [12].

Agora aplicamos perturbações randômicas no parâmetro $p$ do mapa (2.3) e obtemos o mapa (2.4)

$$
\begin{aligned}
& x_{i+1}=a+b\left(x_{i} \cos \theta_{i}-y_{i} \operatorname{sen} \theta_{i}\right), \\
& y_{i+1}=b\left(x_{i} \operatorname{sen} \theta_{i}+y_{i} \cos \theta_{i}\right),
\end{aligned}
$$


com

$$
\theta_{i}=k-\frac{p_{i}}{1+x_{i}^{2}+y_{i}^{2}}
$$

Os parâmetros $a, b$ e $k$ são fixos e $p_{i}$ é o parâmetro de randomicidade, dado por

$$
p_{i}=\bar{p}+\Delta_{p} r_{i}
$$

onde $r_{i}$ é uma variável randômica, como no caso do mapa de Hénon. Na Fig. 2.5(a) plotamos o espaço de fase do mapa de Ikeda com os seguintes parâmetros: $a=0,85$, $b=0,9, k=0,4, \bar{p}=8$ e $\Delta_{p}=0$ no instante $t=250$ de $10^{4}$ condições iniciais tomadas em $-2 \leq x \leq 2$ e $-2 \leq y \leq 2$. Na Fig. 2.5(b) fixamos $\Delta_{p}=0,5$. Como esperávamos, a Fig. 2.5(b) não apresenta a característica fractal do atrator de Ikeda. Introduzindo o fator randômico no parâmetro $p$, obtemos o atrator instantâneo na Fig. 2.5(c), com $2 \times 10^{4}$ condições iniciais. A Fig. 2.5(d) apresenta uma ampliação da região destacada em Fig. 2.5(c), onde notamos a presença de estruturas do tipo Cantor.

\subsection{Mapa de Zaslavsky}

Muitos processos químicos e biológicos em fluidos são caracterizados por uma distribuição filamental de partículas ativas ao longo de conjuntos invariantes da dinâmica caótica da advecção. Sabemos que uma nuvem inicial de partículas adveccionadas por um fluido pode se distribuir sobre um conjunto fractal no espaço [6]. Nesta seção, apresentamos um mapa randômico, o mapa de Zaslavsky, que modela o movimento de partículas flutuantes sobre a superfície de um fluido confinado com uma complicada* dependência do tempo. As partículas podem tanto se agrupar num único ponto ou vários pontos, como também, dependendo dos parâmetros, distribuírem-se sobre um conjunto fractal de dimensão entre um e dois [13].

O mapa randômico de Zaslavsky é dado por

$$
\begin{aligned}
& x_{n+1}=\left[x_{n}+y_{n} \frac{\left(1-e^{-\alpha}\right)}{\alpha}\right] \bmod 2 \pi, \\
& y_{n+1}=\kappa \operatorname{sen}\left(x_{n+1}+\theta_{n}\right)+e^{-\alpha} y_{n},
\end{aligned}
$$

onde $\theta_{n}$ é randomicamente tomado no intervalo $[0,2 \pi]$ a cada iteração. Escolhendo os parâmetros $\alpha=0,09$ e $\kappa=0,5$, obtemos uma estrutura fractal das partículas sobre o fluido [6]. Para $10^{6}$ condições iniciais distribuídas uniformemente em $0 \leq x \leq 2 \pi \mathrm{e}-2 \leq y \leq 2$,

\footnotetext{
*Yu et al. [13] prefere chamar a dependência irregular do fluido no tempo de "complicada" e reservar a palavra caos para designar o comportamento do movimento das partículas no fluido.
} 
(a)

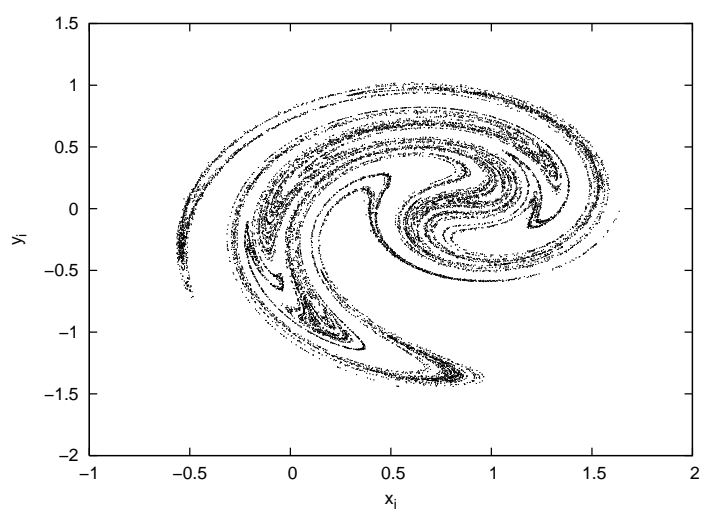

(c)

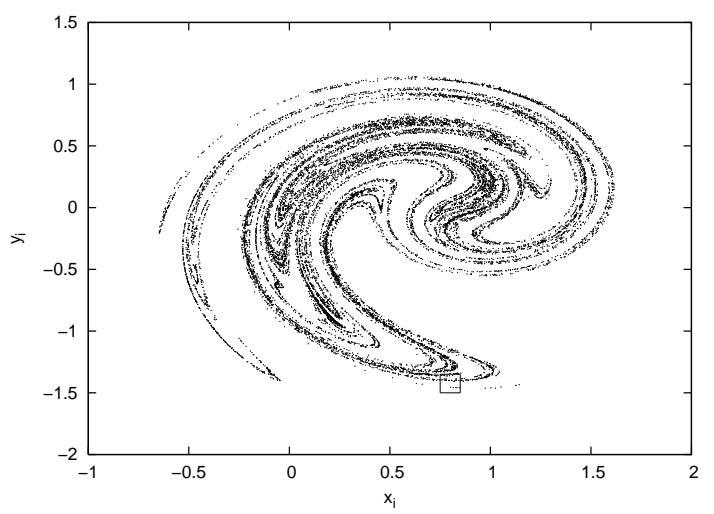

(b)

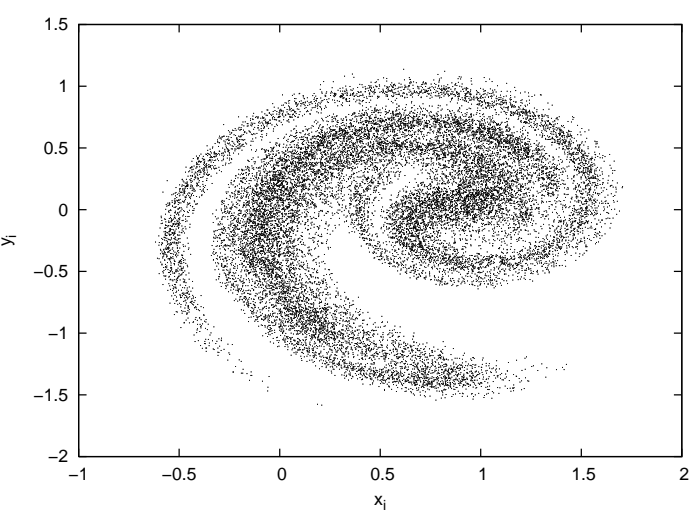

(d)

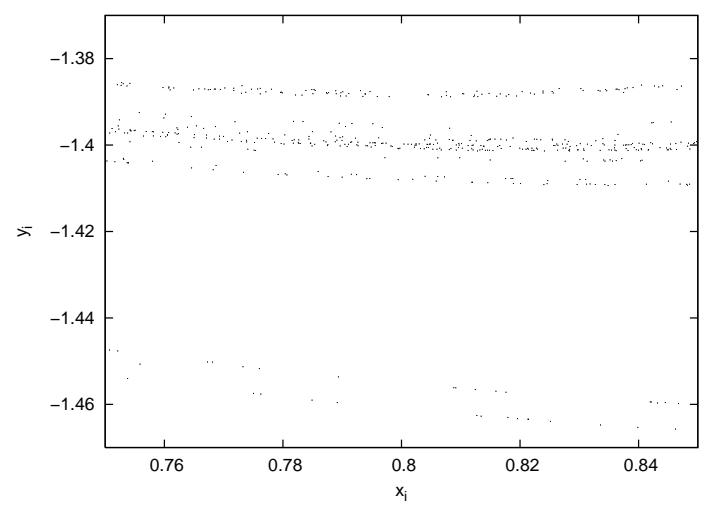

Figura 2.5: Mapa de Ikeda. Em (a) temos o espaço de fase para $2 \times 10^{4}$ condições iniciais tomadas no instante $t=250$ para o mapa com parâmetros fixos; em (b) temos o espaço de fase para uma única condição inicial iterada $2 \times 10^{4}$ vezes sob o mapa randômico e novamente o que vemos é uma versão "granulada" do atrator original. Para (c), plotamos o espaço de fase em $t=250$ para $2 \times 10^{4}$ condições iniciais e em (d) mostramos a ampliação da região destacada em (c), agora com $4 \times 10^{5}$ condições iniciais, onde é possível notar a presença de estruturas tipo Cantor.

calculamos a órbita de cada partícula usando a mesma sequiência randômica $\theta_{i}$ e após um tempo $t=100$ plotamos o espaço de fase (atrator instantâneo), mostrado na Fig. 2.6.

No cálculo da dimensão do atrator, utilizamos o método da contagem de caixas, equivalente à dimensão capacidade. Dividimos o espaço $(x, y) \in[0,2 \pi] \times[-2,2]$ em caixas de tamanho $2 \pi / 2^{n}$ por $4 / 2^{n}$. Determinamos a fração $\mu_{i}$ das órbitas na caixa $i$ no tempo em que o atrator foi tomado e calculamos a inclinação do gráfico de $C(n) \times n$, com $C(n) \equiv-\log _{2} \Sigma_{i} \mu_{i}^{2}$. A inclinação da reta que melhor ajusta os pontos é o valor da dimensão para aquela seqüência randômica. Esse cálculo foi feito para 40 seqüências $\theta_{n}$ diferentes e as pequenas variações nos valores da dimensão estão consistentes com uma distribuição 


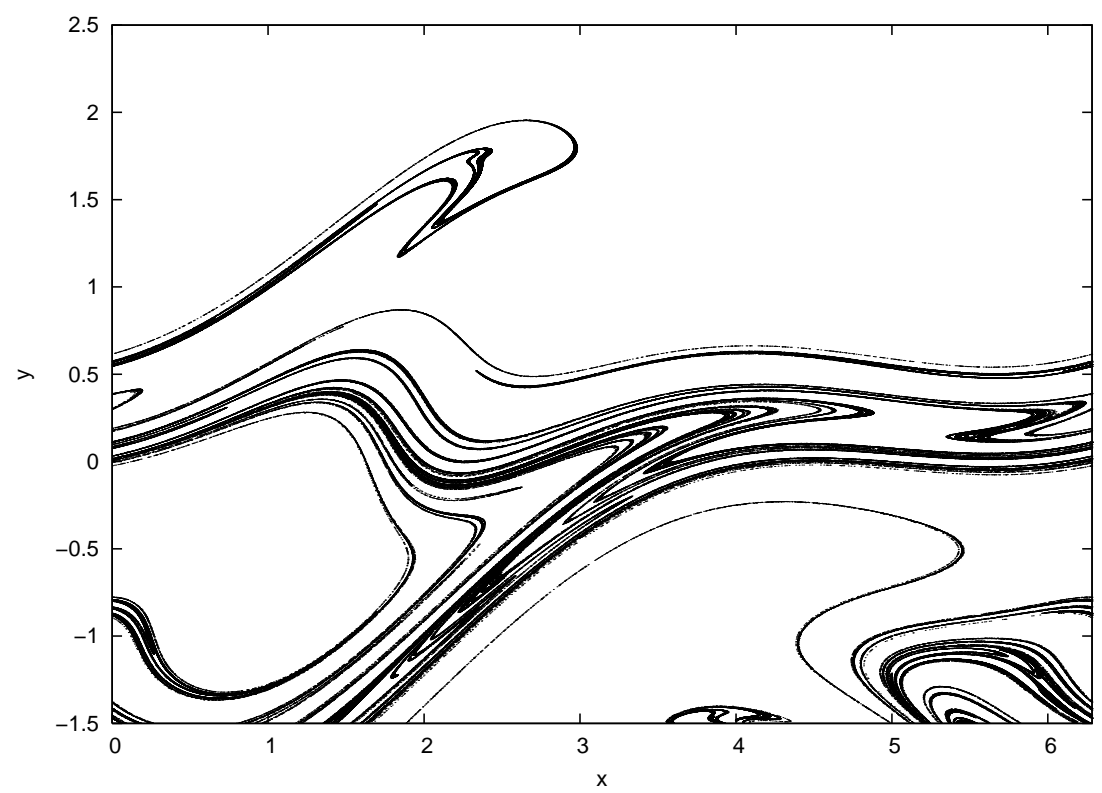

Figura 2.6: Atrator instantâneo para uma seqüência randômica $\theta_{n}$. Os parâmetros foram escolhidos de modo que as partículas estejam distribuídas sobre um conjunto fractal. Temos $\alpha=0,09$ e $\kappa=0,5$ para $10^{6}$ condições iniciais distribuídas uniformemente em $0 \leq x \leq 2 \pi \mathrm{e}-2 \leq y \leq 2$. Para todas as partículas utilizamos a mesma seqüência randômica $\theta_{n}$ e iteramos o mapa por 100 vezes.

gaussiana [6]. O valor médio para a dimensão dessas seqüências é $\bar{d}=1,367 \pm 0,010^{\dagger}$. Namenson et al. [6] ainda comparam os valores da dimensão obtidos por outros métodos, a fim de estabelecer uma relação entre o número espectral e a dimensão.

\footnotetext{
†Para o cálculo da dimensão através da contagem de caixas, Namenson et al. [6] obtiveram $\bar{d}=1,391 \pm$ 0,010 .
} 


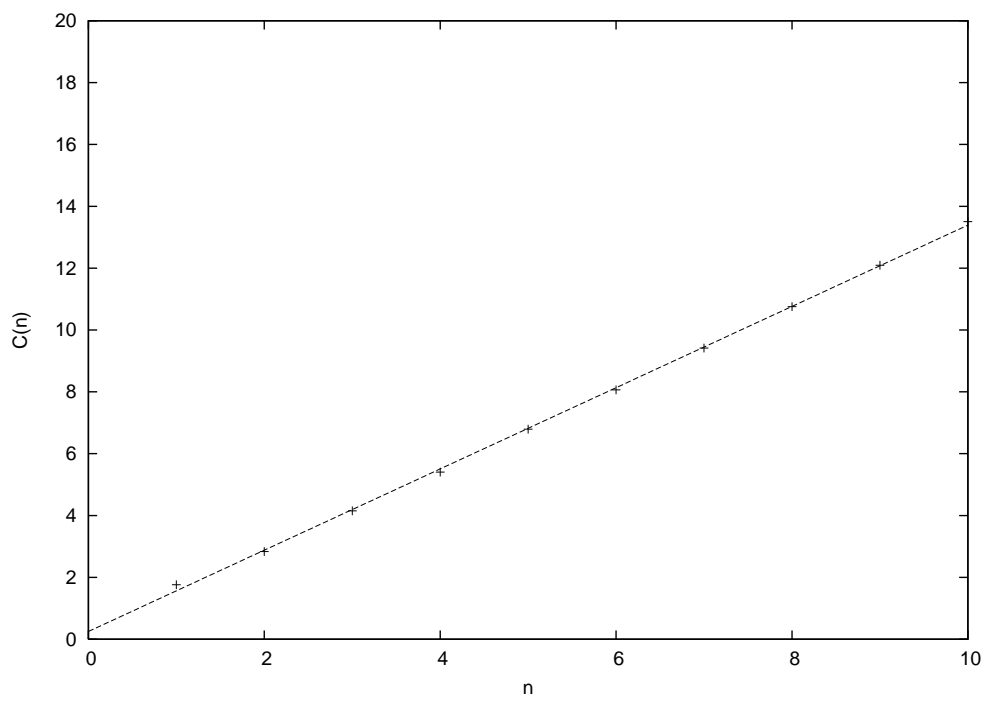

Figura 2.7: Gráfico de $C(n) \times n$ para uma sequência $\theta_{n}$. A quantidade $C_{n}$ é $C(n) \equiv-\log _{2} \Sigma_{i} \mu_{i}^{2}$, com $\mu_{i}$ sendo a fração das órbitas presentes na caixa $i$ no tempo em que o atrator foi tomado. Calculamos a dimensão de 40 sequiências $\theta_{n}$ diferentes e as pequenas variações nos valores da dimensão estão consistentes com uma distribuição gaussiana [6]. O valor médio que encontramos foi $\bar{d}=1,367 \pm$ 0,010 . 


\section{Capítulo 3}

\section{Espalhamento Caótico}

Uma partícula vem do infinito e encontra uma região espalhadora. Durante um certo tempo essa partícula interage com a região e depois escapa para o infinito novamente. Em muitos problemas desse tipo, a dinâmica pode ser caótica e está associada a um fenômeno chamado espalhamento caótico [4]. A natureza caótica do problema de espalhamento é revelada pela existência de uma função de espalhamento, relacionando o estado final com o estado inicial do sistema e que possui uma complexa estrutura fractal, com um conjunto de Cantor de singularidades.

Os trabalhos já realizados sobre espalhamento caótico contribuíram ao esclarecimento da fenomenologia do espalhamento caótico, da estrutura dos conjuntos fractais invariantes responsáveis pelo caos observado e do papel das órbitas periódicas instáveis na determinação do processo de espalhamento. Dentre os resultados desses trabalhos, temos que condições iniciais sobre um conjunto de Lebesgue de medida zero no espaço de fase levam a órbitas confinadas na região de espalhamento por um tempo arbitrariamente longo, devido à existência de conjuntos invariantes instáveis na região do potencial. As órbitas confinadas estão na variedade estável desses conjuntos invariantes. No caso do espalhamento regular, o conjunto invariante pode ser muito simples, por exemplo, tendo poucas órbitas regulares isoladas e suas variedades estáveis e instáveis. No caso do espalhamento caótico, o conjunto invariante é complexo, envolvendo estruturas do tipo Cantor em todas as escalas [8].

Devido à presença desses conjuntos caóticos, os processos de espalhamento exibem duas características proeminentes. Primeiro, a trajetória da partícula pode ser muito complicada na região do potencial, mesmo quando o tempo em que permanece na região espalhadora é finito. Segundo, se construirmos um gráfico de alguma variável que caracteriza o estado inicial versus uma variável que caracteriza o estado final, esta função pode ser muito complicada e possuir extrema sensibilidade às condições iniciais. Especificamente, a função é singular ("infinitamente sensível") sobre um conjunto de Cantor de condições 
iniciais. Além disso, este conjunto de Cantor é justamente o conjunto de condiçoes iniciais sobre a variedade estável do conjunto invariante.

A fim de estudar um problema clássico de espalhamento caótico, seguiremos neste capítulo o trabalho de Bleher et al. [2], que trata de situações com potenciais de espalhamento que exibem uma transição abrupta do comportamento regular para o caótico, quando a energia atinge um valor crítico, $E_{m}$, que é igual ao valor máximo do potencial. Vejamos o seguinte exemplo de espalhamento caótico que ocorre para a Hamiltoniana

$$
H(\mathbf{r}, \mathbf{p})=\frac{p^{2}}{2 m}+V(\mathbf{r}), \quad \text { com } \quad \lim _{|\mathbf{r}| \rightarrow \infty} V(\mathbf{r})=0
$$

O potencial na Hamiltoniana em duas dimensões é dado por

$$
V(x, y)=x^{2} y^{2} \exp \left[-\left(x^{2}+y^{2}\right)\right]
$$

cujos máximos estão em $(x, y)=( \pm 1, \pm 1)$. Para esse potencial $V(x, y)$ a energia máxima é $E_{m}=e^{-2}$. As equações de Hamilton para uma partícula de massa unitária são

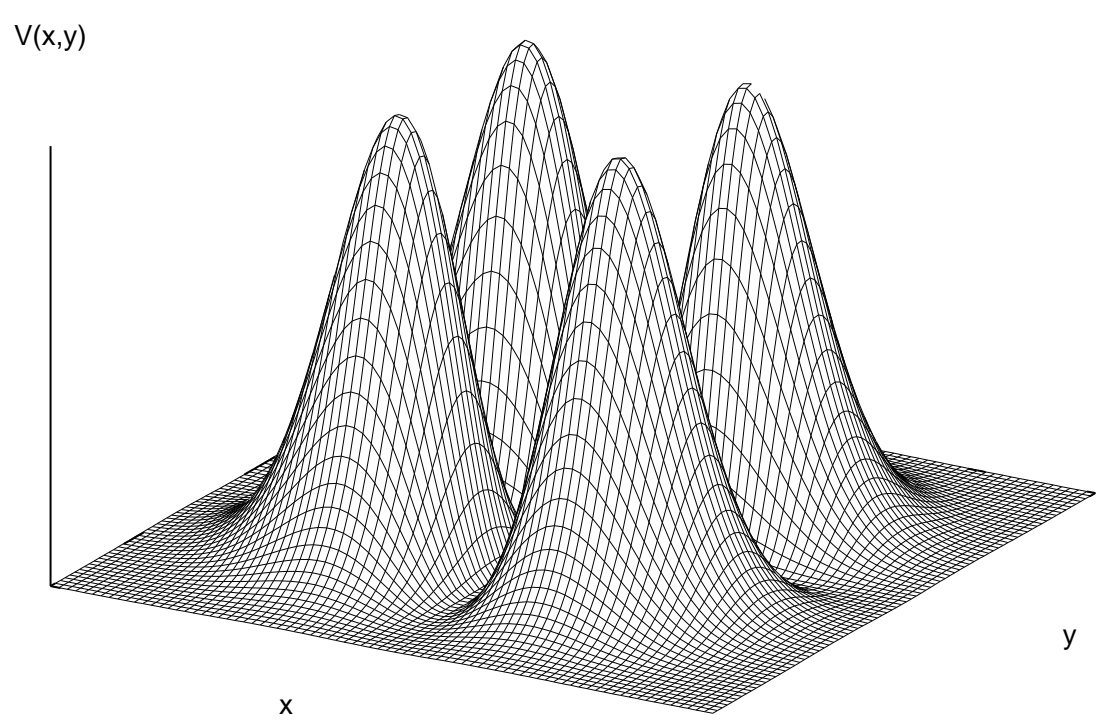

Figura 3.1: Gráfico do potencial dado pela Eq. (3.1). Os máximos desse potencial estão localizados nos pontos $(x, y)=( \pm 1, \pm 1)$ e a energia máxima é $E_{m}=e^{-2}$. 


$$
\begin{aligned}
\dot{\mathbf{r}} & =\mathbf{p}, \\
\dot{\mathbf{p}} & =-\nabla \mathbf{V} .
\end{aligned}
$$

onde $\mathbf{r}=(x, y)$ e $\mathbf{p}=\left(p_{x}, p_{y}\right)$. Tomamos a situação em que partículas vindas do infinito incidem em uma região em torno da origem e depois saem para o infinito novamente. $\mathrm{Na}$ Fig. 3.2 plotamos o ângulo de espalhamento $\phi$ versus o parâmetro de impacto $b$ de 600 condições iniciais tomadas em $x=5$ e $y$ variando de $y=-3$ até $y=3$, de forma que o parâmetro de impacto é a própria coordenada inicial $y$. O ângulo de espalhamento é definido como o ângulo entre a trajetória inicial da partícula e a trajetória com que a partícula abandona a região de espalhamento. Tais condições iniciais foram evoluídas segundo as Eqs. (3.2) e com energia $E=0,220$ (abaixo do valor crítico $E_{m}$ ) e $E=0,035$ (acima do valor crítico $E_{m}$ ), respectivamente. Vemos que acima do valor crítico da energia surgem singularidades no gráfico do ângulo de espalhamento pelo parâmetro de impacto.

(a)

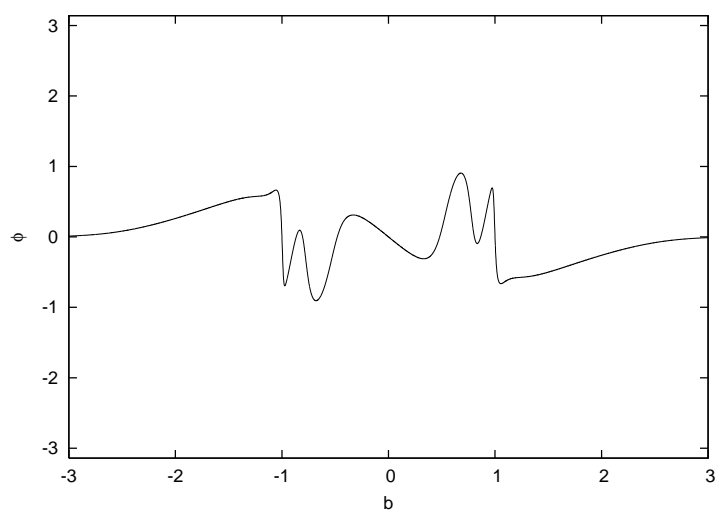

(b)

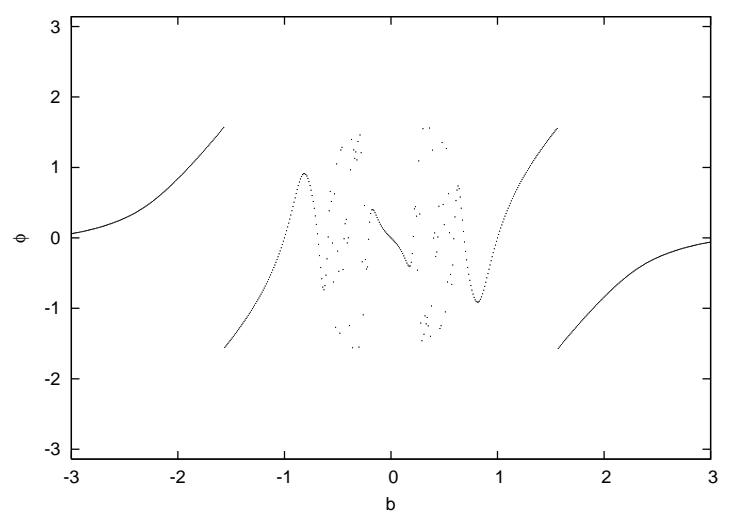

Figura 3.2: Para 600 condições iniciais distribuídas uniformemente na reta $x=5$ e $-3 \leq y \leq 3$, plotamos o ângulo de saída pelo parâmetro de impacto para diferentes valores da energia. Em (a) temos $E=0,220$ e em (b) temos $E=0,035$. Abaixo do valor crítico, $E_{m}=e^{-2}=0,13533 \ldots$, surgem singularidades na função de espalhamento.

O potencial dado pela Eq. (3.1) apresenta quatro picos em torno da origem, como mostra a Fig. 3.1. A partícula que incide nessa região ricocheteia por um tempo entre esses picos do potencial e este tempo é definido como tempo de interação. Na Fig. 3.3, consideramos o tempo em que as condições iniciais permanecem confinadas na região determinada por $\left(x^{2}+\right.$ $\left.y^{2}\right)^{1 / 2}<5$ e plotamos o tempo de interação para diferentes valores do parâmetro de impacto b. Quando comparamos as singularidades dos gráficos das Figs. 3.2(b) e 3.3 notamos que elas coincidem, ou seja, singularidades no gráfico do tempo de interação correspondem a singularidades na função de espalhamento.

A presença de tempos de interação infinitos deve-se à existência de um conjunto caótico 


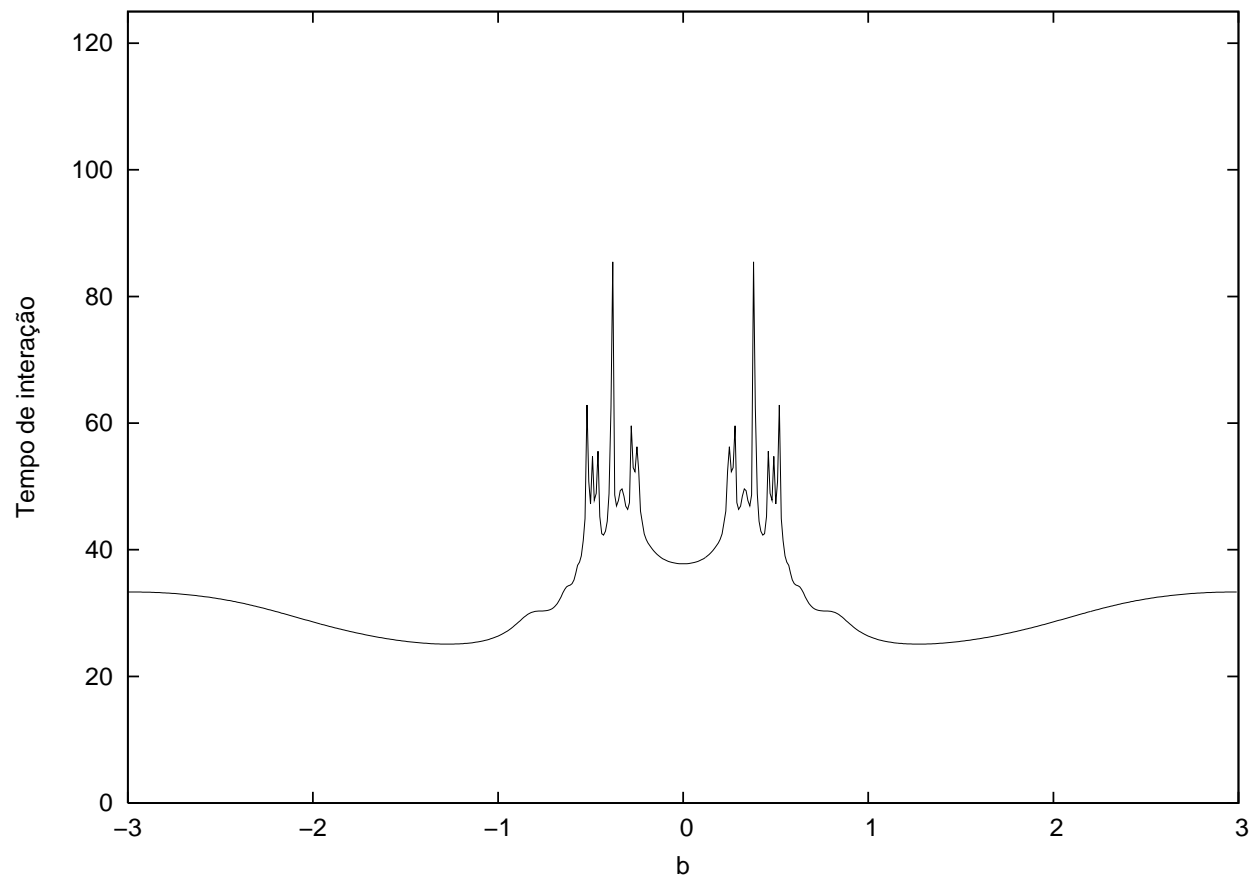

Figura 3.3: Tempo de interação versus parâmetro de impacto.

não-atrator limitado no espaço de fase. As órbitas sobre esse conjunto invariante permanecem para sempre na região do potencial, tanto para $t \rightarrow+\infty$ quanto para $t \rightarrow-\infty$. Esse conjunto caótico é essencialmente a interseção de suas variedades instáveis e estáveis, cada uma consistindo de um conjunto de Cantor de duas superfícies aproximadamente paralelas no espaço de fase tridimensional [2]. Para mostrar que as singularidades da função de espalhamento estão associadas a uma estrutura fractal, vamos calcular a dimensão do conjunto.

\subsection{Dimensão Fractal}

A sensibilidade às condições iniciais é uma característica conhecida dos sistemas caóticos. Pequenas mudanças nas condições iniciais levam a mudanças significativas na dinâmica do sistema ao longo do tempo. Sistemas dinâmicos não-lineares tipicamente possuem mais de um estado assintótico. Para tais sistemas, o acesso a um estado ou a outro depende das condições iniciais [3].

Uma condição inicial é considerada $\varepsilon$-incerta se ela está localizada a uma distância $\varepsilon$ da fronteira da bacia de atração. Nessa situação, nós não podemos prever para qual atrator a órbita seguirá, para uma precisão $\varepsilon$. A fração de condições iniciais que são $\varepsilon$-incertas, $f(\varepsilon)$, está relacionada com $\varepsilon$ por

$$
f(\varepsilon) \sim \varepsilon^{\alpha} .
$$


Para $\alpha<1$, dizemos que existe sensibilidade às condições iniciais. De fato, é comum o caso $\alpha<1$ e nessa condição um aumento substancial na incerteza da condição inicial resulta numa incerteza relativamente pequena em relação ao estado final medido por $f$.

Utilizamos a dimensão capacidade, definida por

$$
d=\lim _{\delta \rightarrow 0} \frac{\ln N(\delta)}{\ln (1 / \delta)}
$$

onde $N(\delta)$ é o número mínimo de cubos de dimensão $D$, com lado $\delta$, necessários para cobrir a fronteira da bacia de atração num espaço de fase cuja dimensão relevante seja $D$. Em geral a dimensão da fronteira satisfaz a relação $d \geq D-1$, pois a fronteira divide o espaço de fase. O expoente $\alpha$ está relacionado com a dimensão da fronteira por [3,14]

$$
\alpha=D-d
$$

Para uma fronteira simples temos $d=D-1$, o que pela Eq. (3.4) resulta em $\alpha=1$. Para uma fronteira fractal, $d>D-1$ e (3.4) dá $\alpha<1$ (isto é, um estado final sensível). A relação entre o expoente $\alpha$ e a dimensão da fronteira é resultado da dimensão capacidade através do seguinte raciocínio: tomando o lado do cubo $\delta$ do tamanho da incerteza $\varepsilon$, o volume da região incerta do espaço de fase será da ordem do volume total de todos $N(\epsilon)$ os cubos necessários para cobrir a fronteira da bacia. Como o volume de um cubo $D$-dimensional é $\varepsilon^{D}$, o volume da região incerta no espaço de fase é da ordem de $\varepsilon^{D} N(\varepsilon)$. Considerando que $N(\varepsilon) \sim \varepsilon^{-d}$ satisfaz a Eq. (3.3), usamos essa aproximação para estimar o volume incerto do espaço de fase como $\varepsilon^{D} N(\varepsilon) \sim \varepsilon^{D-d}$.

Para calcular numericamente a dimensão fractal, dividimos os valores do parâmetro de impacto em duas partes, o conjunto de valores de $b$ chamado $S^{+}$, que corresponde às órbitas que possuem ângulo de espalhamento positivo $(\phi>0)$, e o conjunto de valores de $b$ que corresponde às órbitas cujos ângulos de espalhamento são negativos $(\phi<0)$, chamado $S^{-}$. Esses conjuntos, $S^{+}$e $S^{-}$, consistem de dois intervalos disjuntos ao longo do eixo $b$ e, no interior de cada intervalo, $\phi$ varia suavemente $\operatorname{com} b$. Para muitos pontos na fronteira desses intervalos a função de espalhamento é singular e é nisso que estamos interessados. Assumimos que a dimensão capacidade deste conjunto será a mesma para o conjunto de pontos na fronteira entre $S^{+}$e $S^{-}$. Para um determinado valor de incerteza $\varepsilon$, escolhemos randomicamente um grande número de pares do parâmetro de impacto, $b_{i}$ e $b_{i} \pm \varepsilon$, onde o sinal positivo ou negativo é escolhido randomicamente. Se o estado final (para cima ou para baixo) da órbita perturbada é diferente do estado final da órbita não-perturbada, então o estado da órbita não-perturbada é contado como incerto quando a perturbação tem 


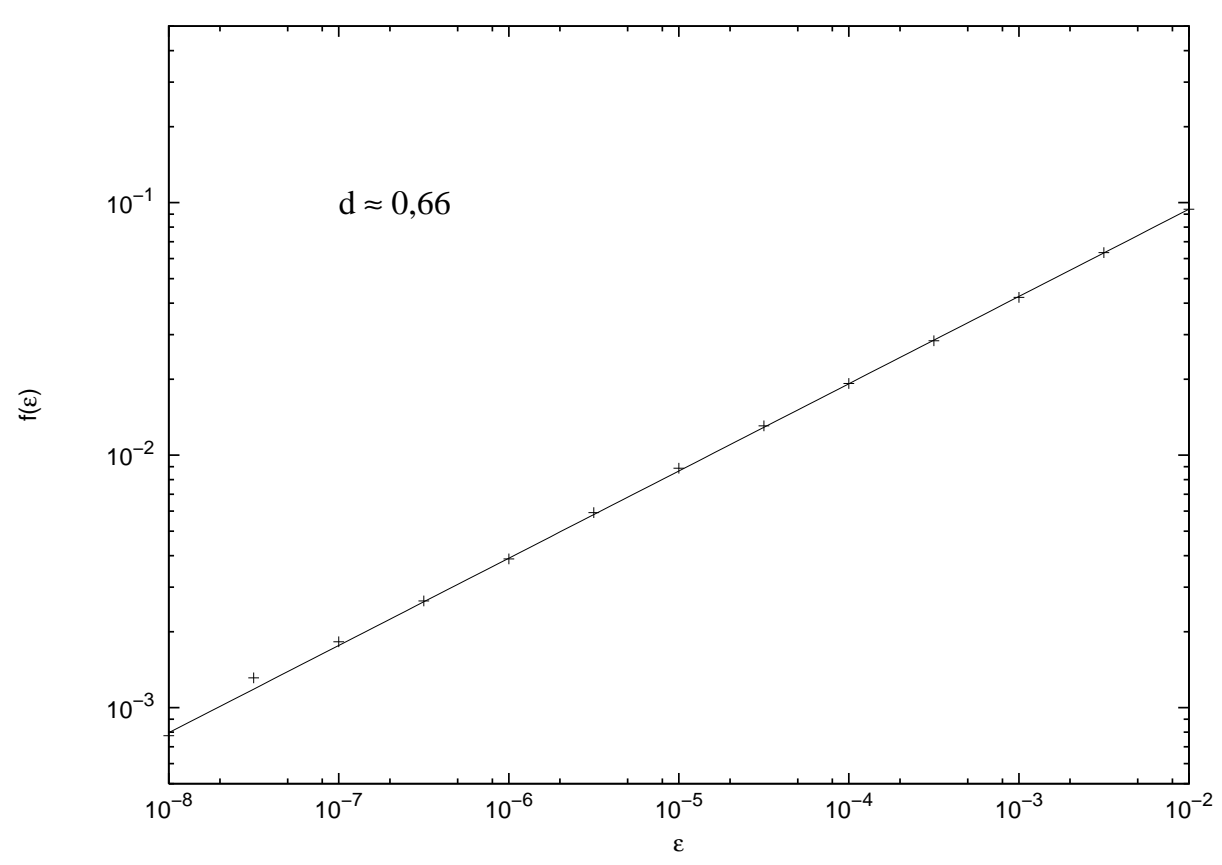

Figura 3.4: Cálculo da dimensão através da fração incerta. Para $10^{4}$ condições iniciais tomadas em $-2 \leq y \leq 2$ e $x=5 \operatorname{com} E / E_{m}=0,26$, temos a dimensão aproximadamente igual à 0,66 .

magnitude $\varepsilon$. Repetimos esse procedimento para várias condições iniciais e contamos o número de pares cujos estados finais são incertos, a fim de determinar a fração média $\bar{f}(\varepsilon)$ de órbitas que são incertas sob uma perturbação de magnitude $\varepsilon$. Das definições de $f$ e $\bar{f}$, esperamos que $f$ seja aproximadamente proporcional à média $\bar{f}$ e então, $\bar{f} \sim \varepsilon^{D-d}$ [3]. A Fig. 3.4 mostra o gráfico $\log -\log$ de $f(\varepsilon) \times \varepsilon$, no qual obtivemos a dimensão $d \cong 0$, 66 para $10^{4}$ condições iniciais tomadas em $-2 \leq y \leq 2$ e $x=5$, quando $E / E_{m}=0,260^{*}$.

Outra maneira de estudar a estrutura fractal no espalhamento caótico é considerar partículas com condições iniciais sobre uma superfície bidimensional no espaço de fase e determinar se os ângulos das velocidades assintóticas $t \rightarrow+\infty$ estão no intervalo $0<\phi \leq \pi$ (saída para cima) ou no intervalo $-\pi<\phi \leq 0$ (saída para baixo). Qual destas saídas se aplica a uma órbita depende de sua condição inicial e estamos interessados em quais condições iniciais estão associadas a uma saída e quais condições estão associadas a outra. Tomamos a seção transversal bidimendional $y_{0}=0$ no espaço de fase das condições iniciais. Escolhemos condições iniciais de uma dada energia num intervalo de valores $-3 \leq x_{0} \leq 3$. Para cada $x_{0}$ escolhemos um grande número de ângulos das velocidades iniciais no intervalo $\theta_{0} \in(-\pi, \pi]$. Então, para cada condição inicial integramos a órbita correspondente e determinamos por onde ela sai. Se a partícula tem o ângulo da velocidade de saída posi-

*Na referência [2], Bleher et al. determinaram $d \cong 0,67$. 
(a) $E=E_{m}$

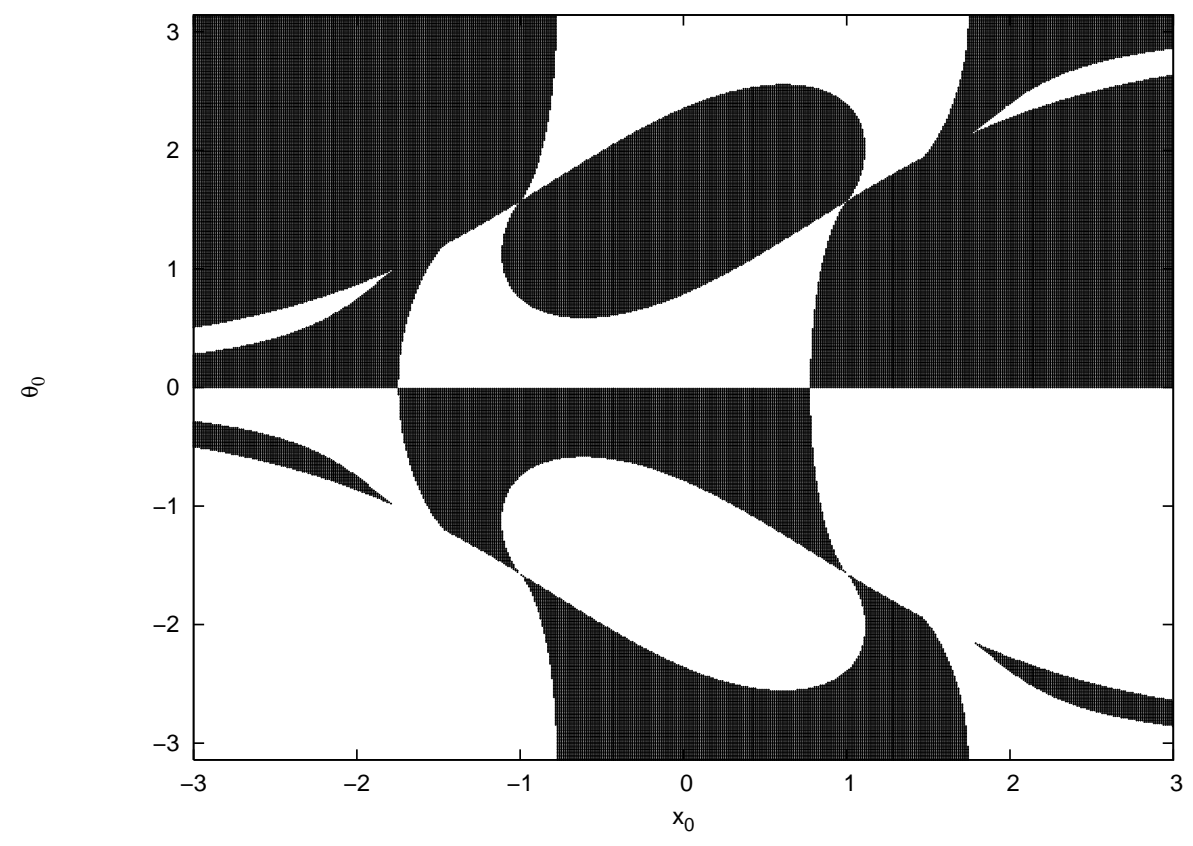

(b) $E / E_{m}=0,600$

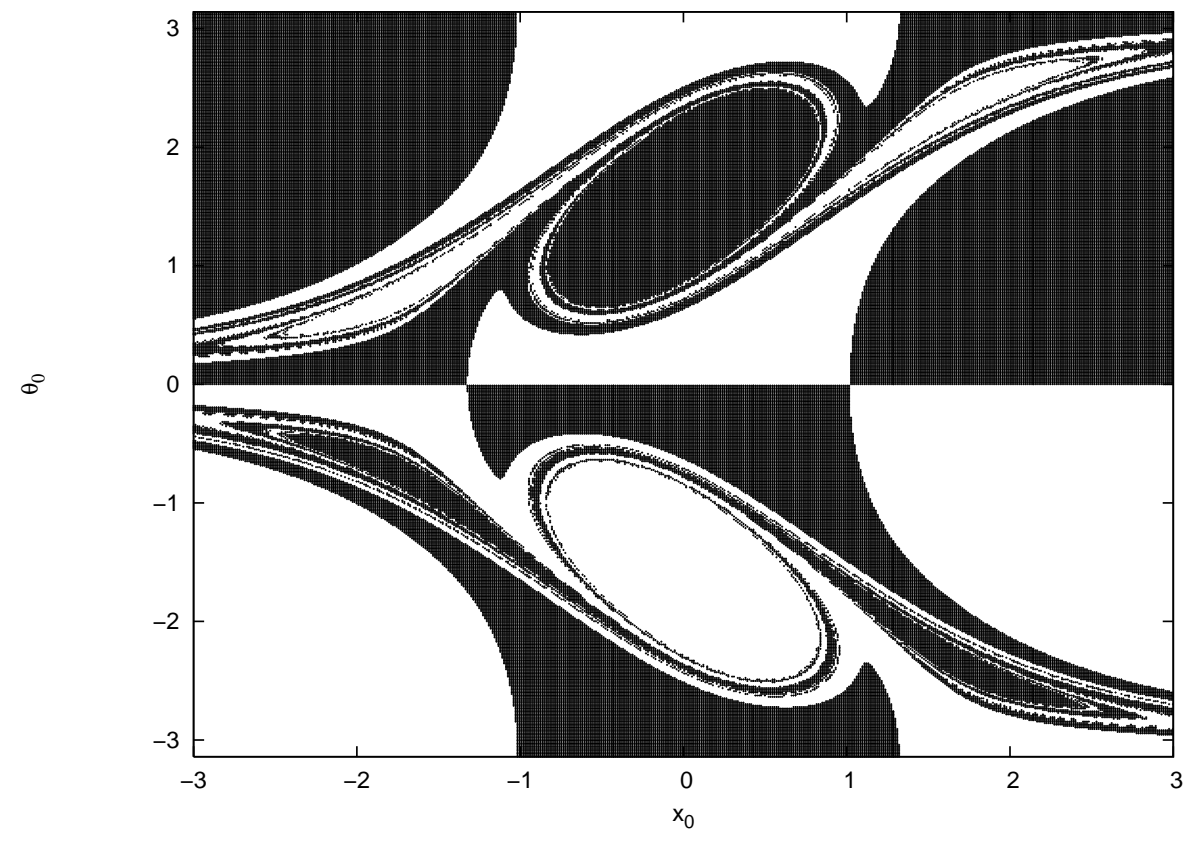

Figura 3.5: Gráfico de uma grade de $512 \times 512$ condições iniciais distribuídas uniformemente em $-3 \leq x_{0} \leq 3$ e $-\pi<\theta \leq \pi$, com $y_{0}=0$ e energias diferentes para (a) e (b). Em (a) $E=E_{m}$ e em (b) $E / E_{m}=0,6$. 
(c) $E / E_{m}=0,260$

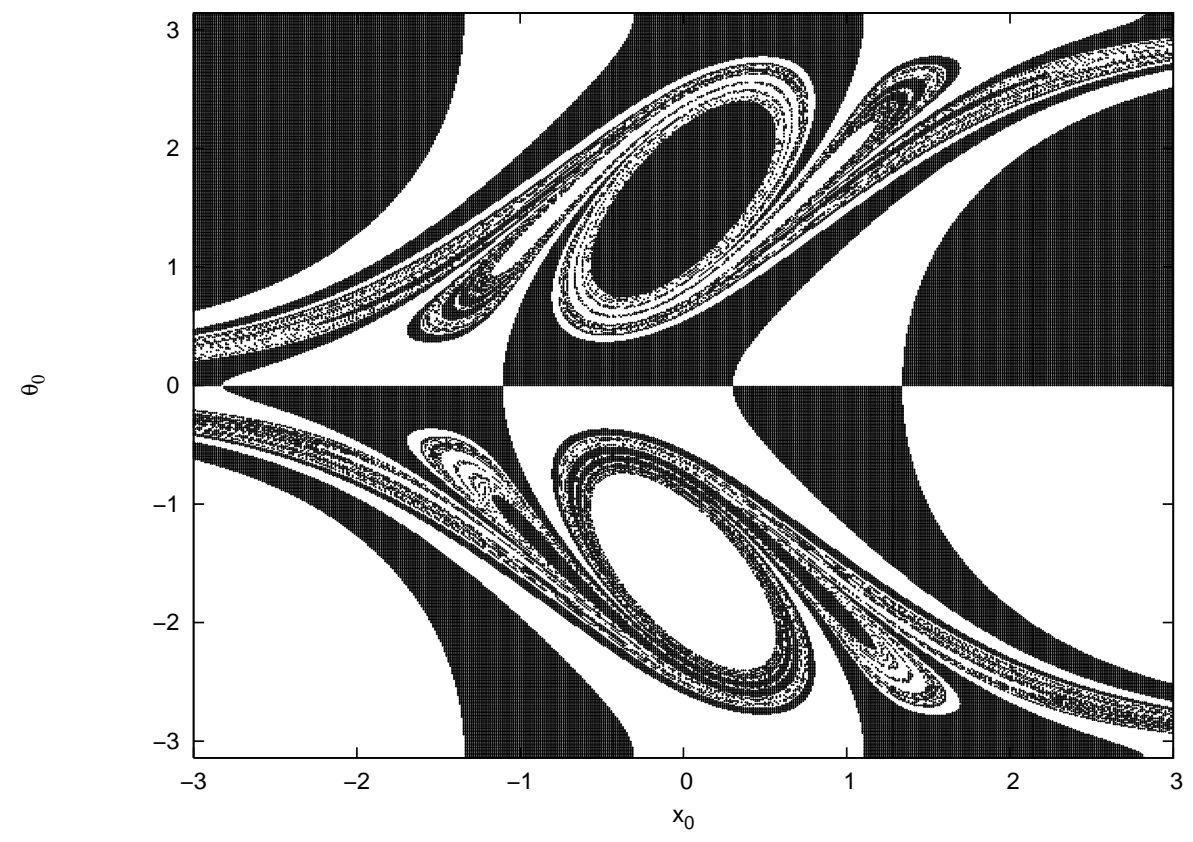

(d) $E / E_{m}=0,037$

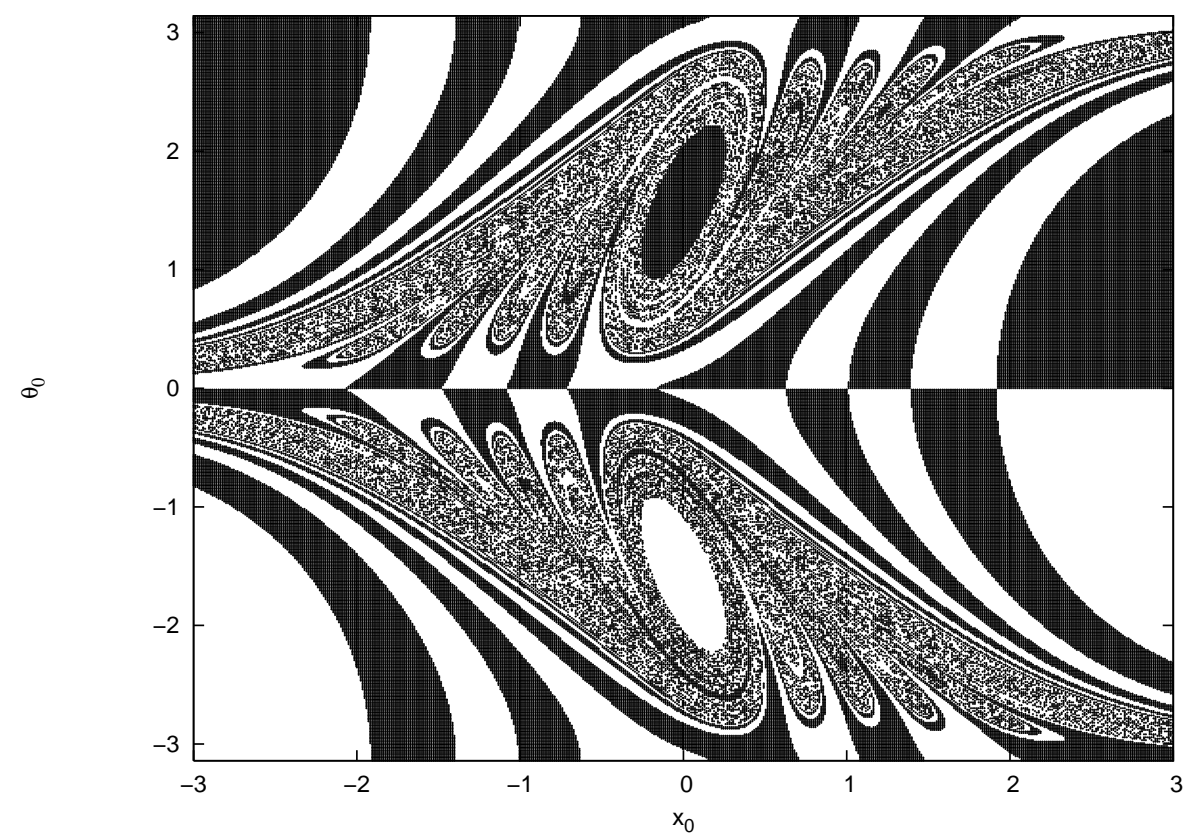

Figura 3.6: (Continuação da Fig. 3.5). Para as mesmas condições iniciais da Fig. 3.5, com diferentes valores de energia. $\operatorname{Em}(\mathrm{c}), E / E_{m}=0,260 \mathrm{e} \mathrm{em}(\mathrm{d}), E / E_{m}=0,037$. Quando o valor da razão $E / E_{m}$ é menor do que 1 , a fronteira entre as regiões clara e escura apresenta uma estutura fina e complexa.

tivo (saída para cima), então plotamos a condição inicial. A Fig. 3.5(a) mostra tal situação quando $E=E_{m}$, onde a fronteira que separa as regiões claras (saída para baixo) e escuras 
(saída para cima) é aparentemente suave. As figuras seguintes são do mesmo tipo, porém para valores menores da energia $E$. Temos $E / E_{m}=0,6$ para a Fig. 3.5(b), $E / E_{m}=0,26$ para a Fig. 3.6(a) e $E / E_{m}=0,037$ para a Fig. 3.6(b).

\subsection{Sela Caótica}

Para as condições iniciais da Fig. 3.6 (c), plotamos aquelas que possuem os maiores tempos de interação na Fig. 3.7 (a). Comparando a Fig. 3.7 (a) com a Fig. 3.3 vemos que o tempo de interação diverge para órbitas com parâmetros de impacto nos quais a função de espalhamento é singular. A correspondência entre a região de singularidades da função de espalhamento e os gráficos das fronteiras das bacias sugere que as regiões fractais nos gráficos das fronteiras estão associadas às órbitas com longo tempo de interação. As órbitas que correspondem às singularidades na função de espalhamento são assintóticas às órbitas aprisionadas e, portanto, localizam-se sobre os ramos das variedades estáveis das órbitas aprisionadas. A variedade instável do conjunto de órbitas aprisionadas é obtido da mesma maneira: as órbitas iteradas para trás no tempo que possuem os maiores tempos de interação têm condições iniciais muito próximas às das órbitas aprisionadas. Na Fig. 3.7 (b) temos a superfície de seção correspondente à Fig. 3.7 (a) da variedade instável.

O conjunto das interseções da variedade estável com a variedade instável constitui a sela caótica ou sela estranha. Na Fig. 3.8 temos os pontos que permanecem por mais tempo na região de espalhamento, tanto para $t \rightarrow+\infty$ quanto para $t \rightarrow-\infty$.

\subsection{Transição para o Caos}

Até agora estudamos um caso de bifurcação abrupta do comportamento regular regular para o espalhamento caótico e vimos características importantes de problemas de espalhamento, como as singularidades da função de espalhamento associadas a um conjunto fractal de condições iniciais. A questão agora é: dado um conjunto de parâmetros nos quais o espalhamento é regular, quais são as seqüências típicas de eventos (rotas) que ocorrem enquanto os parâmetros variam e o espalhamento torna-se caótico? Nesta seção, seguimos o trabalho de Ding et al. [8] e estudamos a rota de bifurcação sela-centro através de um modelo em particular.

Partindo de um estágio onde o espalhamento é regular, observamos que a bifurcação sela-centro marca a transição do espalhamento regular para o caótico. Imediatamente após essa bifurcação, as variedades estável e instável da nova sela intersecionam-se formando um 
(a)

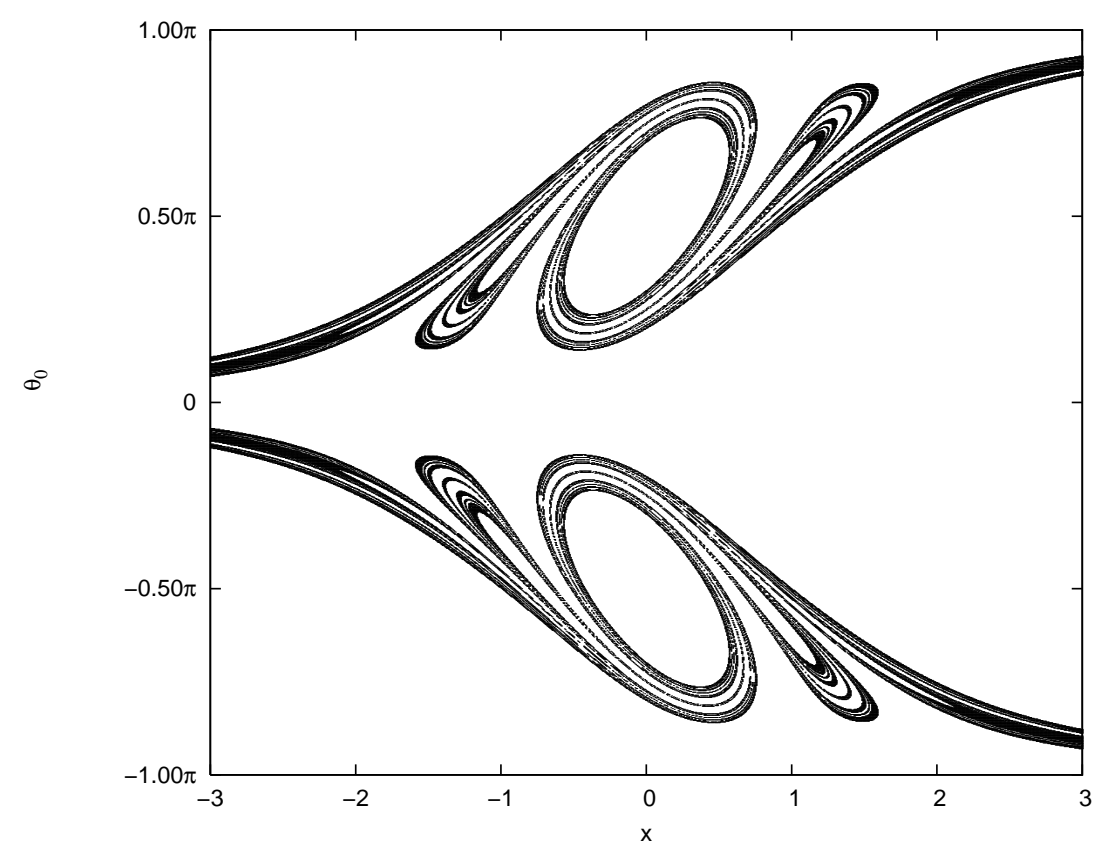

(b)

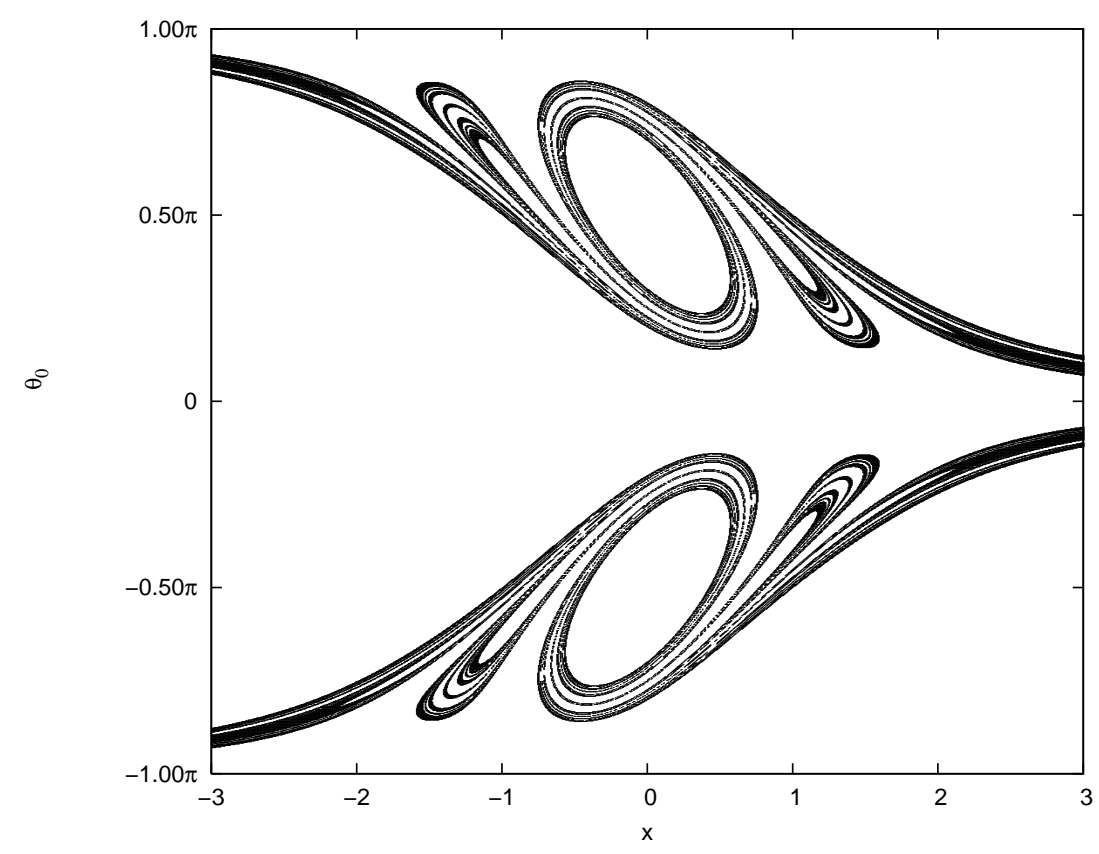

Figura 3.7: Gráfico da interseção da (a) variedade estável e (b) da variedade instável das órbitas aprisionadas com o plano $y_{0}=0 \mathrm{em} E / E_{m}=0,260$. A simetria entre (a) e (b) deve-se ao fato que o sistema é conservativo e simétrico sob a reversão do tempo. 


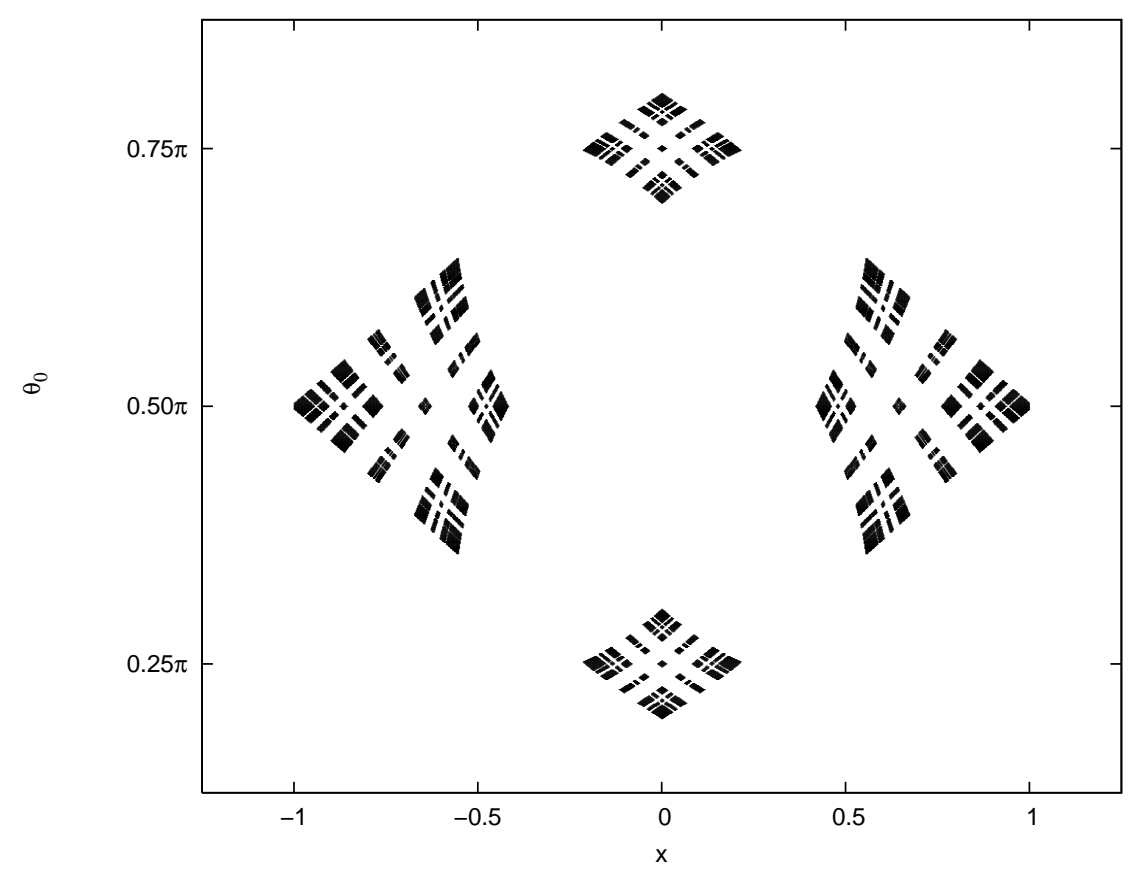

Figura 3.8: Conjunto de pontos que possuem os maiores tempos de interação.

conjunto caótico. O próximo estágio importante na evolução do espalhamento caótico nesse modelo é a ocorrência de uma tangência heteroclínica entre a variedade estável e a variedade instável da sela recém surgida e as variedades estável e instável de outra sela que surge durante a evolução do sistema. Este evento não provoca apenas uma mudança qualitativa no conjunto caótico, mas marca o início da formação de uma estrutura topologicamente equivalente a um mapa tipo ferradura.

O potencial usado no estudo da rota de bifurcação consiste de três picos não-sobrepostos, cujos centros estão sobre os vértices de um triângulo isósceles, como mostra a Fig. 3.9. Cada pico é individualmente simétrico e pode ser representado por

$$
\Phi_{i}=V_{i}\left[1-\frac{\left(x-x_{i}\right)^{2}+\left(y-y_{i}\right)^{2}}{a_{i}}\right] \text {, }
$$

para

$$
\left(x-x_{i}\right)^{2}+\left(y-y_{i}\right)^{2} \leq a_{i}^{2},
$$

$\mathrm{e}$

$$
\Phi_{i}=0 \quad \text { para } \quad\left(x-x_{i}\right)^{2}+\left(y-y_{i}\right)^{2}>a_{i}^{2} .
$$

Na Eq. (3.5), o índice $i$ é $i=1,2,3$ e o ponto $\left(x_{i}, y_{i}\right)$ é o centro do i-ésimo pico, $a_{i}$ é o raio do pico e $V_{i}$ é a altura do pico. O sistema de coordenadas é tal que a reta vertical que passa pelo centro de 2 é o eixo $y$ e a reta horizontal que corta os centros de 1 e 3 é o eixo $x$ e a 
interseção dos eixos $x$ e $y$ é a origem. O potencial total é então simétrico em relação ao eixo $y$ e pode ser escrito como

$$
\Phi(x, y)=\Phi_{1}(x, y)+\Phi_{2}(x, y)+\Phi_{3}(x, y) .
$$

Como cada pico do potencial é um parabolóide de revolução, a equação de movimento pode ser resolvida exatamente dentro de cada uma das regiões $\left(x-x_{i}\right)^{2}+\left(y-y_{i}\right)^{2} \leq a_{i}^{2}$, não sendo necessário integrar numericamente equações diferenciais. No estudo desse potencial, a configuração geométrica do potencial, isto é, $x_{i}, y_{i}, a_{i}$, a energia da partícula $E_{p}$ e as alturas dos potenciais $V_{1}=V_{3}>E_{p}$ são mantidas fixas enquanto o potencial $V_{2}$ é variado, de forma que investigamos como o sistema comporta-se como função do parâmetro de controle $V_{2}$.

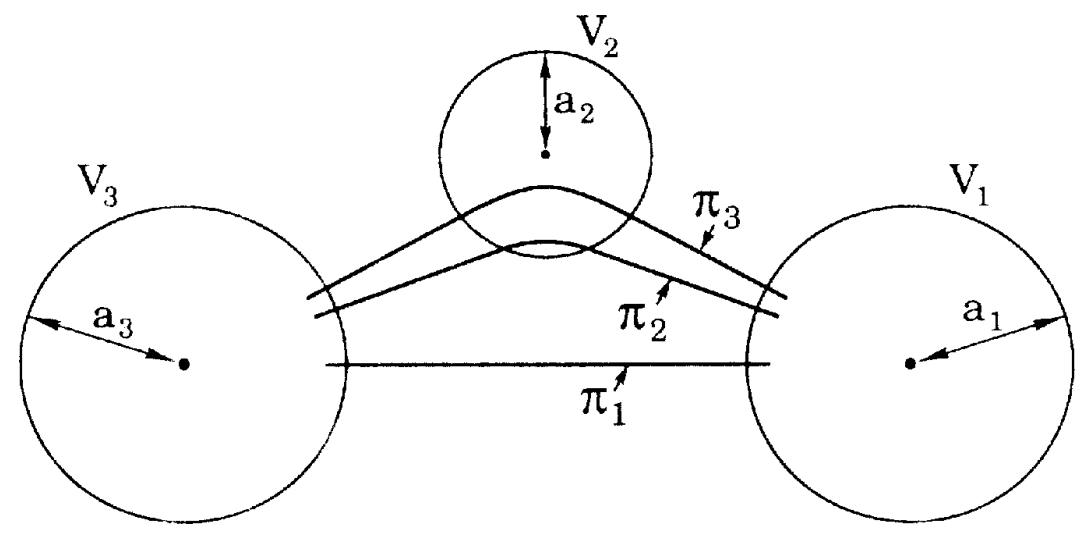

Figura 3.9: O potencial definido pelas Eqs. (3.5) e (3.6) consiste de três picos não-sobrepostos e individualmente simétricos. O sistema de coordenadas é tal que a reta vertical que passa pelo centro de 2 é o eixo $y$ e a reta horizontal que corta os centros de 1 e 3 é o eixo $x$ (Ding et al. [8]).

Primeiramente, ao tomarmos $V_{2}=0$ obtemos um caso de espalhamento regular, devido à simples configuração de dois picos idênticos. A altura dos potenciais é presumidamente maior do que a energia das partículas e existe uma órbita periódica $\pi_{1}$ presa entre os dois potenciais ao longo da linha que une seus centros. A órbita $\pi_{1}$ e suas variedades estável e instável são o único conjunto invariante neste caso (Fig. 3.10).

Na Fig. 3.11 temos os gráficos do ângulo de espalhamento versus o parâmetro de impacto e do tempo de saída versus o parâmetro de impacto. O ângulo de espalhamento varia de $[-\pi, \pi]$ e é o ângulo entre a velocidade com que a partícula deixa a região do potencial $\Phi=\Phi_{1}+\Phi_{3}$ e o eixo $y$. O tempo de saída é definido como o tempo entre a primeira vez que a igualdade $\left(x-x_{i}\right)^{2}+\left(y-y_{i}\right)^{2}=a_{i}^{2}$ é satisfeita para algum $i$, até que a partícula satisfaça pela última vez $\left(x-x_{i}\right)^{2}+\left(y-y_{i}\right)^{2}=a_{i}^{2}$ para algum $i$. Na Fig. 3.11(b) notamos a existência de um pico, indicando que para um valor do parâmetro de impacto existe um tempo de saída 


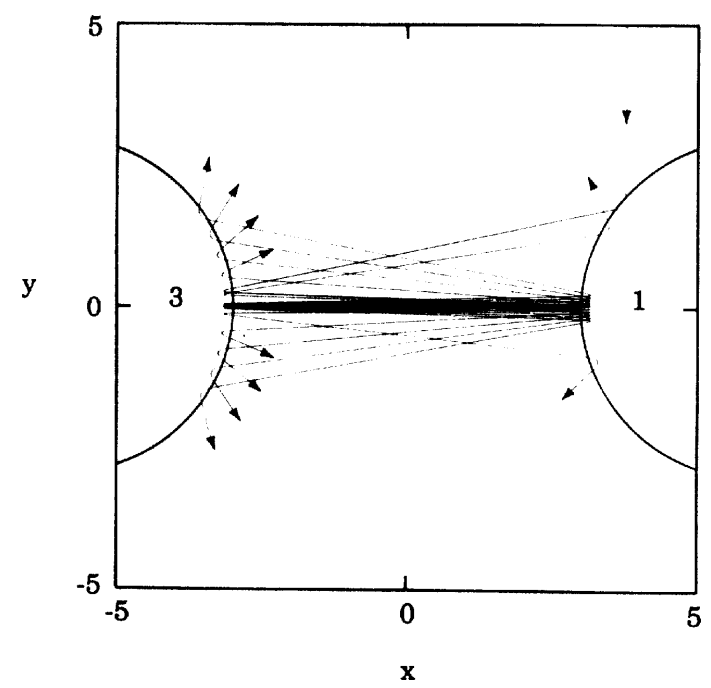

Figura 3.10: Tomando $V_{2}=0$, o sistema de dois picos idênticos apresenta espalhamento regular e possui uma órbita periódica. Aqui temos as trajetórias de dez partículas com condições iniciais $y_{0}=6$ e $x_{0}$ entre 3,7564 e 3,7566. Essas partículas ricocheteam durante algum tempo mas acabam deixando a região do potencial (Ding et al. [8]).

(a)

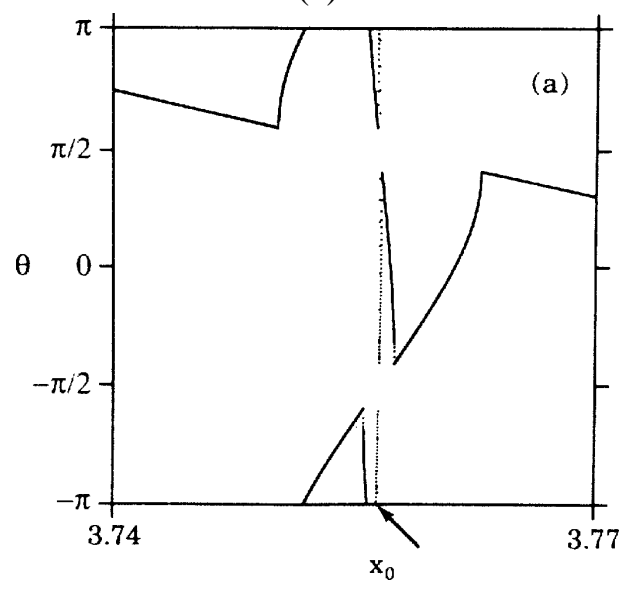

(b)

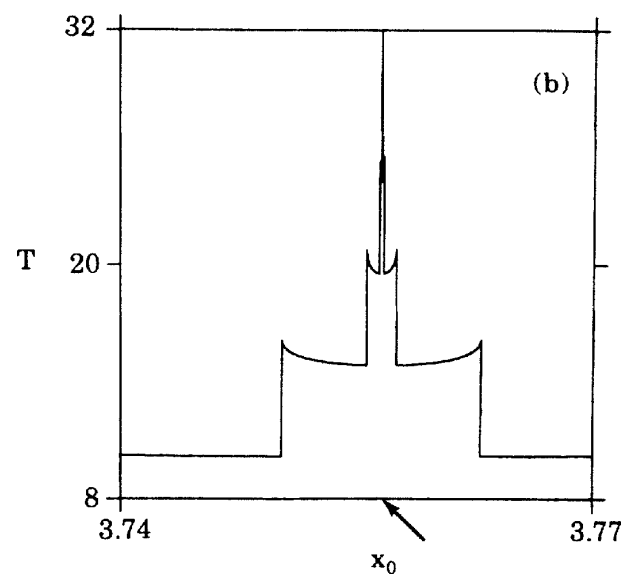

Figura 3.11: (a) e (b) mostram o ângulo de saída e o tempo de interação versus o parâmetro de impacto na situação mais simples, quando temos $V_{2}=0$ e o espalhamento então é regular (Ding $e t$ al. [8]).

infinito. Esse valor do parâmetro de impacto, indicado pela seta nas Figs. 3.11(a) e (b), corresponde à interseção da variedade estável da órbita $\pi_{1}$ com a reta de condições iniciais $y=6$.

Quando consideramos a presença do potencial $\Phi_{2}$, fazendo $V_{2} \neq 0$, o quadro já não é o mesmo do espalhamento regular. A primeira mudança significativa ocorre quando $V_{2}=$ 
(a)

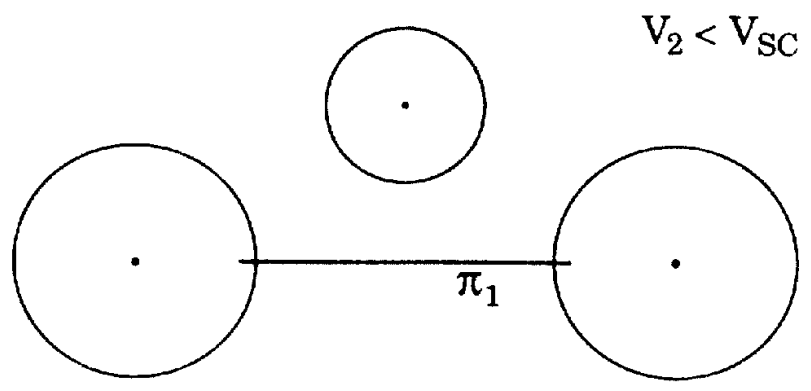

( b )

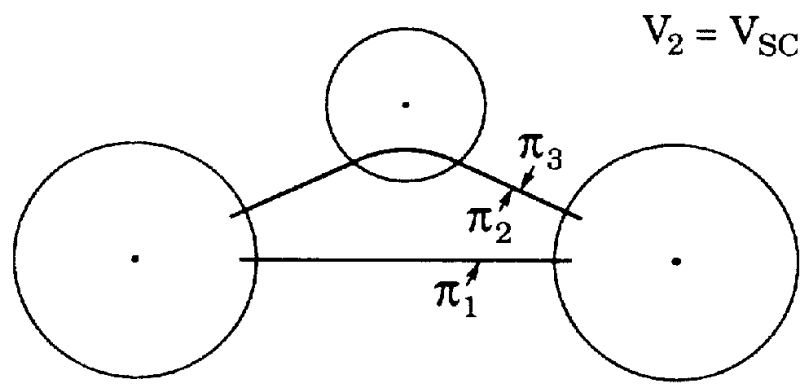

(c)

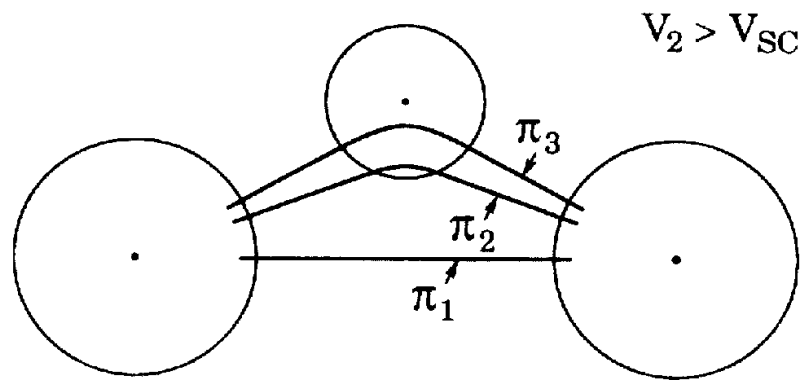

Figura 3.12: A única órbita periódica para $V_{2}<V_{s c}, \pi_{1}$, está representada em (a). Em (b) estão a sela recém criada $\pi_{3}$ e o centro $\pi_{2}$, que coincidem um com o outro em $V_{2}=V_{s c}$. Em (c), $\pi_{2}$ e $\pi_{3}$ separam-se quando $V_{2}>V_{s c}$ (Ding et al. [8]).

$V_{s c} \approx 0,187$ e temos uma bifurcação sela-centro. Desta bifurcação surge um par de órbitas entre os potenciais $\Phi_{1}$ e $\Phi_{3}$ passando por $\Phi_{2}$. As condições de $\Phi_{1}$ e $\Phi_{3}$ continuam as mesmas. Para $\Phi_{2}$ temos $x_{2}=0, y_{2}=2,2, a_{2}=2$ e $V_{2}>0$.

Aumentando $V_{2}$ um pouco mais, a sela e o centro que inicialmente coincidem, agora separam-se um do outro. A órbita $\pi_{3}$ é uma sela regular (autovalores reais e positivos), enquanto $\pi_{2}$ é um centro (os autovalores são complexos). Conforme a sela e o centro se separam, as variedades estável e instável de $\pi_{3}$ se cruzam transversalmente. De acordo com a teoria de Smale, uma interseção homoclínica implica na existência de um conjunto caótico invariante. Portanto a bifurcação sela-centro marca o início do espalhamento caótico. 

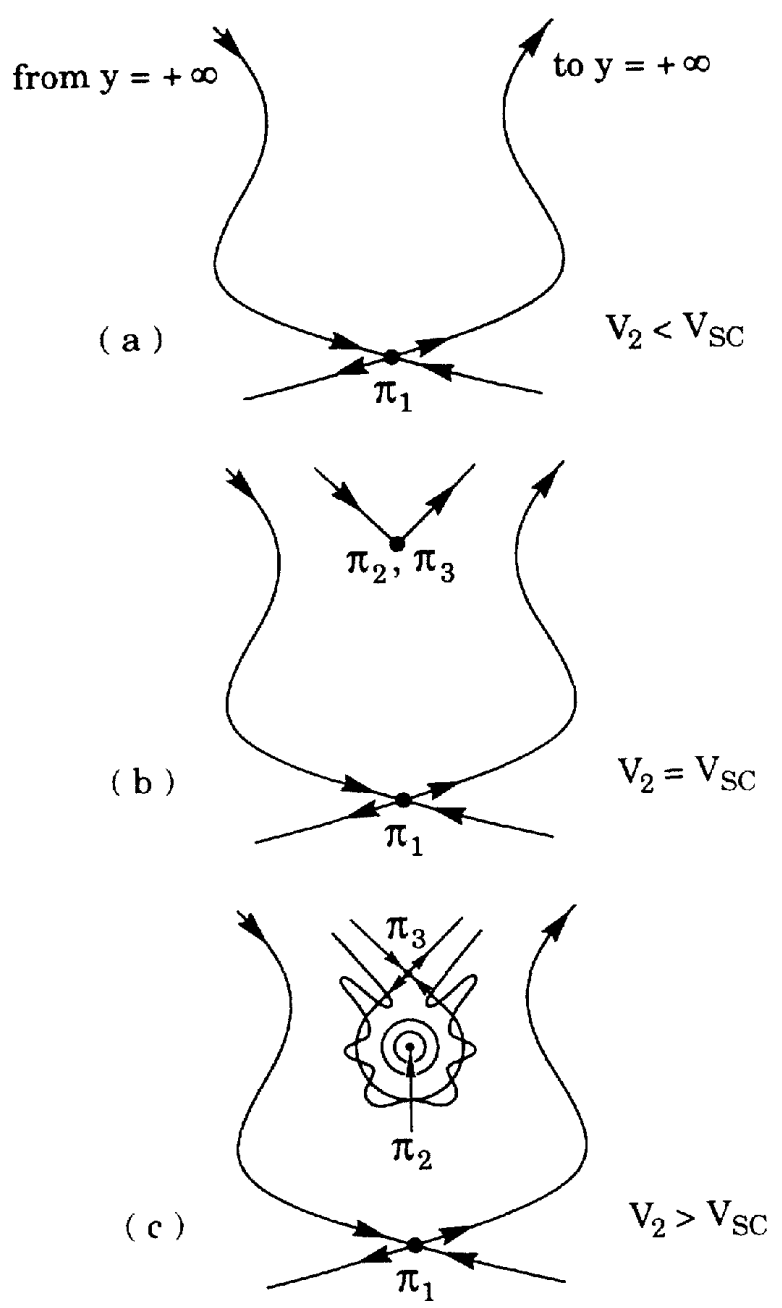

Figura 3.13: (a) $\pi_{1}$ e suas variedades estável e instável quando $V_{2}<V_{s c}$. Em (b), temos a sela e o centro recém criados em $V_{2}=V_{s c}$ e em (c) as interseções homoclínicas que ocorrem entre as variedades estável e instável de $\pi_{3}$ quando $V_{2}>V_{s c}$ (Ding et al. [8]).

A Fig. 3.14 mostra a função de espalhamento para o valor $V=0,195$, correspondente à situação mostrada na Fig. 3.13(c), onde o espalhamento é não-hiperbólico pois temos órbitas regulares. Como já foi dito, os picos observados no gráfico do tempo de saída são as interseções das variedades estáveis com a reta de condições iniciais $y=6$. A principal diferença entre esse caso (onde o conjunto invariante é caótico) e o caso da Fig. 3.11(b) (em que o conjunto invariante não é caótico) está na aparente distribuição dos picos sobre um conjunto de Cantor.

Com o aumento de $V_{2}$ o centro $\pi_{2}$ sofre uma bifurcação de duplicação de período e se torna uma sela instável (autovalores reais e negativos). Evidências numéricas indicam que esse processo de duplicação de período continua ad infinitum. A existência dessa cascata infinita de duplicação de período corrobora com a ocorrência de um número infinito de 
(a)

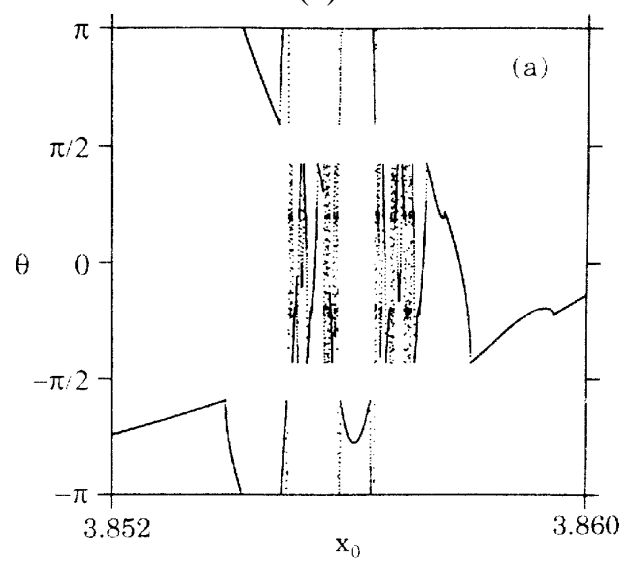

(b)

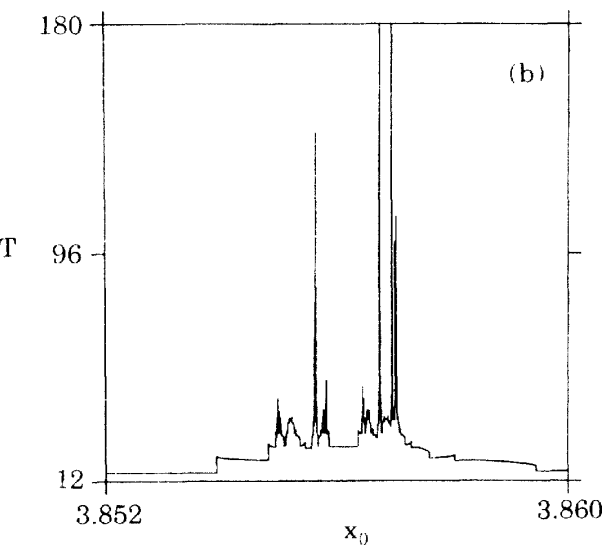

Figura 3.14: Novamente temos a função de espalhamento, ângulo de saída versus parâmetro de impacto, porém após ter ocorrido a bifurcação sela-centro e a interseção homoclínica, marcando o início do espalhamento caótico (Ding et al. [8]).

órbitas periódicas num conjunto caótico [15].

O surgimento de um conjunto caótico depois da bifurcação sela-centro tem um forte impacto no comportamento do sistema. A principal diferença no caso do conjunto invariante ser caótico é que os picos observados no gráfico do tempo de saída residem aparentemente sobre um conjunto de Cantor. Outro ponto é que o caos acontece somente para partículas com ângulo de espalhamento $|\theta|<\pi / 2$, ou seja, para partículas que saem para cima. A função de espalhamento para as partículas $\operatorname{com}|\theta|>\pi / 2$ é regular e essencialmente governada pela sela original $\pi_{1}$ e suas variedades estável e instável. A razão disso pode ser entendida da seguinte maneira. Considere as partículas que experimentam o espalhamento caótico: suas primeiras imagens sobre a superfície de seção estão na região onde ocorre a interseção das variedades estável e instável de $\pi_{3}$. Como podemos ver na Fig. 3.13, esta região está completamente contida entre o ramo da variedade instável de $\pi_{1}$, que vai de $\pi_{1}$ até $y=+\infty$ e o ramo da variedade estável de $\pi_{1}$, que vem de $y=+\infty$ até $\pi_{1}$. Esses ramos formam barreiras que os pontos sobre a superfície de seção não podem ultrapassar. Em outras palavras, a região fechada pelos ramos das variedades de $\pi_{1}$ é invariante sob a dinâmica de espalhamento. Assim as parículas que sofrem espalhamento caótico devem seguir com $|\theta|<\pi / 2$. Por outro lado, se a partícula sai com $|\theta|>\pi / 2$, ela segue o outro ramo da variedade estável de $\pi_{1}$, onde não existe conjunto caótico.

Seguindo com o procedimento de aumentar $V_{2}$ e com o conseqüente afastamento de $\pi_{2}$ e $\pi_{3}$, temos que as variedades estável e instável da sela $\pi_{3}$ são esticadas na direção de $v_{y}$, enquanto as variedades estável e instável de $\pi_{1}$ são comprimidas ao longo da direção $v_{y}$, ocasionando uma tangência heteroclínica em $V_{2}=V_{h 1} \approx 0,215$. Para um valor de 


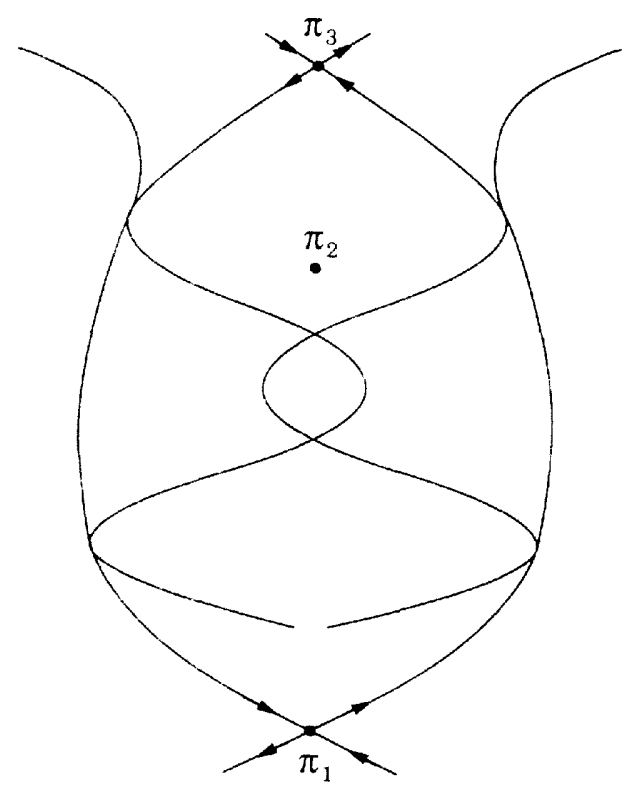

Figura 3.15: Tangência heteroclínica em $V_{2}=V_{h 1}$ (Ding et al. [8]).

$V_{2}$ ligeiramente maior do que $V_{h 1}$, as variedades estável e instável das duas selas cruzam umas com as outras, dando origem às interseções heteroclínicas. O conjunto caótico, que envolvia apenas as variedades de $\pi_{3}$, subitamente aumenta e passa a incluir as variedades de $\pi_{1}$. Considerando que agora o caos não é restrito à região entre as variedades de $\pi_{1}$, existe caos tanto para $|\theta|<\pi / 2$ quanto para $|\theta|>\pi / 2$, como podemos ver pela função de espalhamento na Fig. 3.14. Para o potencial especificado no início desta seção, encontramos numericamente que a Fig. 3.17 se aplica a $V_{2}$ no intervalo $V_{-}<V_{2}<V_{+}<E_{p}$, onde $V_{-} \approx 0,265$ e $V_{+} \approx 0,275$. As Figs. 3.16 ilustram os conjuntos das variedades estáveis e instáveis das selas $\pi_{1}$ e $\pi_{3}$ para cinco casos. Aumentando ainda mais $V_{2}$, as variedades estável e instável de $\pi_{3}$ continuam seu movimento relativo na direção de $v_{y}$, enquanto os ramos superiores das variedades de $\pi_{1}$ movem-se um em direção ao outro. Examinando a situação em que $V_{-}<V_{2}<V_{+}$, não há evidências de órbitas periódicas estáveis ou superfícies KAM, sendo razoável concluir que existe um intervalo $V_{-}^{\prime}<V_{2}<V_{+}^{\prime}$ no qual o conjunto invariante é hiperbólico e este intervalo está contido em $V_{-}<V_{2}<V_{+}$. A dinâmica não pode ser hiperbólica em todo o intervalo $V_{-}<V_{2}<V_{+}$porque existe um número infinito de bifurcações sela-centro na vizinhança de qualquer tangência [8].

Agora considere as regiões $A_{1}, A_{2}$ e $A_{3}$ da Fig. 3.17. Numa analogia com a ferradura de Smale, a Fig. 3.17 foi deformada com o objetivo de produzir um diagrama topologicamente equivalente e o resultado é a Fig. 3.18. O retângulo na Fig. 3.18 leva à região hachurada que contém $A_{1}, A_{2}$ e $A_{3}$. Da teoria da ferradura de Smale sabemos que o conjunto invariante que contém todas as órbitas do retângulo original é um conjunto de Cantor e está completamente 


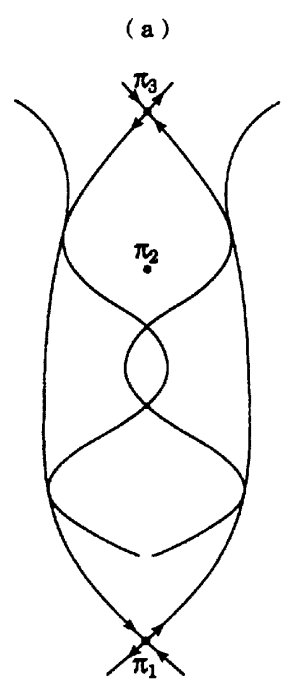

$\mathrm{v}_{2}=\mathrm{v}_{\mathrm{h} 1}$

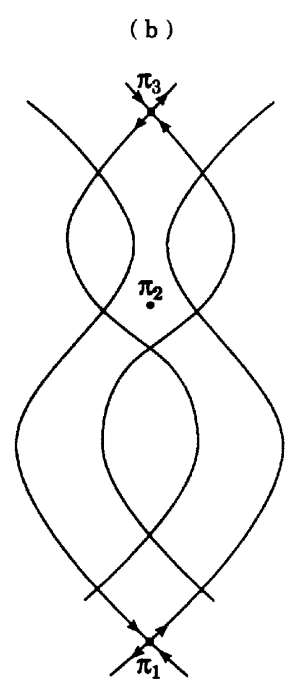

$\mathrm{v}_{\mathrm{h} 1}<\mathrm{v}_{2}<\mathrm{v}_{\text {. }}$

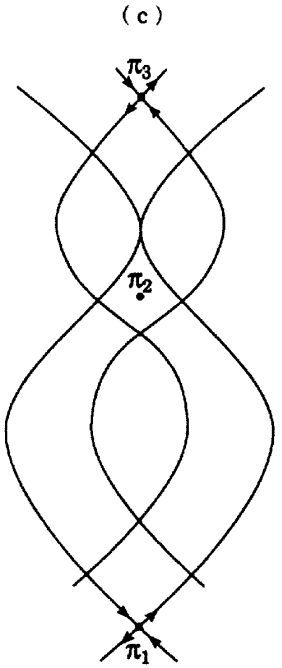

$\mathrm{v}_{2}=\mathrm{v}$.

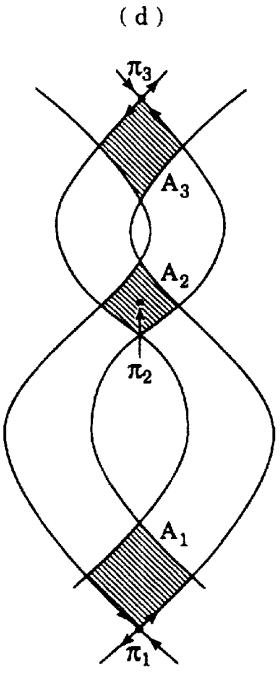

$\mathrm{V}_{.}<\mathrm{V}_{2}<\mathrm{V}_{+}$

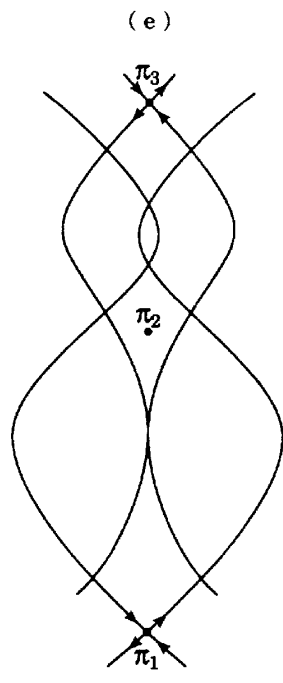

$\mathrm{v}_{2}=\mathrm{v}_{+}$

Figura 3.16: Evolução das variedades estáveis e instáveis de $\pi_{1}$ e $\pi_{3}$ para cinco casos: (a) $V_{2}=V_{h 1}$, (b) $V_{h 1}<V_{2}<V_{-}$, (c) $V_{2}=V_{-}$, (d) $V_{-}<V_{2}<V_{+}$(e) $V_{2}=V_{+}$(Ding et al. [8]).

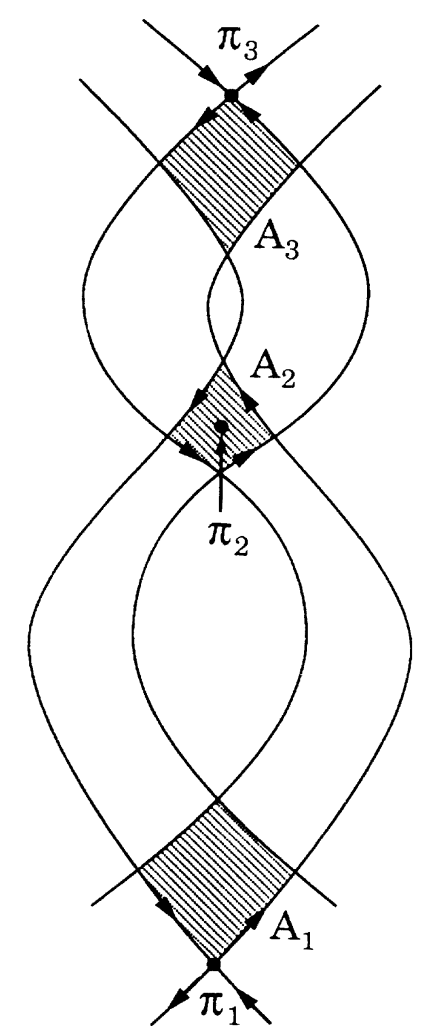

Figura 3.17: As variedades estáveis e instáveis de $\pi_{1}$ e $\pi_{3}$ para $V_{-}<V_{2}<V_{+}$(Ding et al. [8]).

contido nas áreas $A_{1}, A_{2}$ e $A_{3}$ [16].

A fim de concluir esse capítulo, vejamos um resumo dos acontecimentos que consti- 


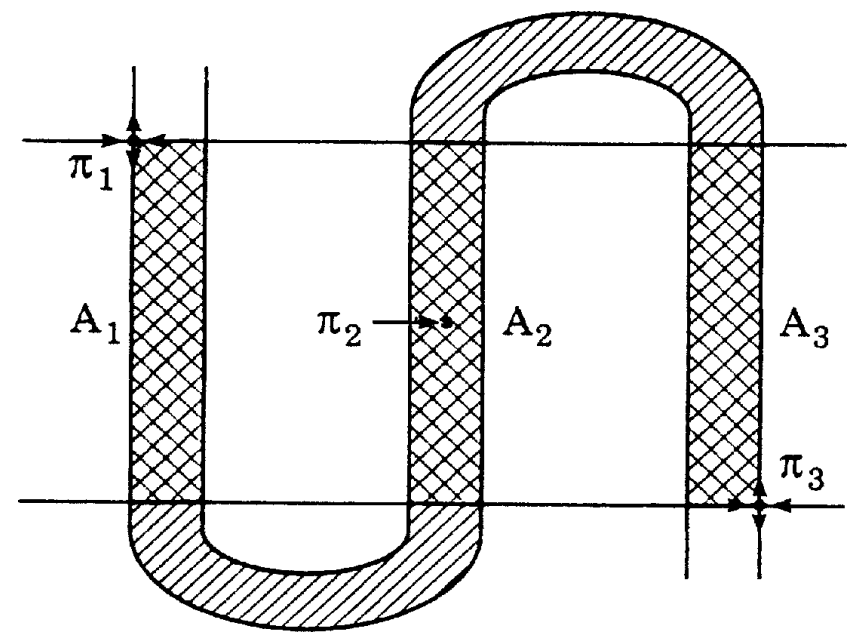

Figura 3.18: Mapa tipo ferradura obtido pela deformação da Fig. 3.17 (Ding et al. [8]).

tuem a rota para o caos. Temos que o espalhamento caótico decorre de uma bifurcação sela-centro e mudanças repentinas na função de espalhamento $\left(\theta \times x_{0}\right)$ são resultado de interseções heteroclínicas sobre a superfície de seção. O espalhamento regular pode ser entendido completamente em termos do número finito de órbitas periódicas instáveis e de suas variedades estável e instável. A transição do espalhamento regular para caótico ocorre via uma bifurcação sela-centro que produz um par de órbitas periódicas. Posteriormente, o centro sofre bifurcação de duplicação de período e torna-se uma sela instável. O conjunto caótico produzido pela bifurcação sela-centro é gerado pela interseção homoclínica das variedades estável e instável da sela criada na bifurcação. Para $V_{2}=V_{h 1}$ acontece a primeira tangência heteroclínica e para de $V_{2}>V_{h 1}$ o processo de espalhamento sofre uma mudança qualitativa súbita, exibindo espalhamento caótico para partículas com ângulo de saída $\theta$, $|\theta|<\pi / 2$ e $|\theta|>\pi / 2$. Quando $V_{-}<V_{2}<V_{+}$o conjunto caótico resultante é completamente hiperbólico.

Para finalizar, lembramos que no caso que abre o capítulo existe uma mudança abrupta do comportamento regular para o comportamento caótico, devido à diminuição no valor da energia das partículas incidentes com uma conseqüente mudança na topologia do sistema. Agora, variando a altura de um dos picos constituintes do potencial, podemos estabelecer uma seqüência de eventos que determinam a evolução do espalhamento regular para o espalhamento caótico. 


\section{Capítulo 4}

\section{Espalhamento Não-Hiperbólico}

Um sistema não-hiperbólico conservativo é caracterizado pela presença de ilhas KAM, com um espaço de fase composto por regiões de movimento regular e regiões de movimento caótico. Em geral, sistemas Hamiltonianos são não-hiperbólicos, com órbitas periódicas estáveis e ilhas KAM. O espalhamento caótico no caso não-hiperbólico tem duas características importantes, muito diferentes do caso em que há espalhamento hiperbólico, que são a dimensão do conjunto invariante e o tempo de decaimento das partículas. No espalhamento caótico, a função de espalhamento é singular sobre um conjunto de Cantor e este conjunto é o responsável pelas órbitas que permanecem na região de espalhamento por longos tempos. Este comportamento da função de espalhamento implica que uma incerteza mínima no estado inicial pode impossibilitar a determinação do estado final. Uma medida quantitativa que caracteriza a magnitude desse efeito é a dimensão fractal do conjunto singular de condições iniciais. Quando o espalhamento caótico é hiperbólico a dimensão fractal é tipicamente maior que 0 e menor que 1 para um segmento de reta de condições iniciais. Se o espalhamento caótico é não-hiperbólico, embora o conjunto singular de condições iniciais possua medida de Lebesgue nula, a dimensão fractal é sempre 1, o que significa que a incerteza na determinação do estado final é maximal. Quanto ao tempo de decaimento, isto é, o número de partículas que permanece na região de espalhamento em cada instante de tempo, no caso não-hiperbólico ele segue uma lei de potência, enquanto no caso hiperbólico é uma exponencial.

A dinâmica das partículas no espalhamento caótico hiperbólico produz um conjunto de Cantor com auto-similaridade estatística e dimensão $d<1$. Um conjunto de Cantor padrão é uma boa aproximação nesse caso e podemos construir tal conjunto da seguinte maneira [4]: existe um intervalo de condições iniciais onde as partículas permanecem na região de espalhamento por um tempo mínimo $T_{0}$. Após um tempo $2 T_{0}$ uma fração $\eta$ dessas partículas escapa da região de espalhamento. Consideramos que as condições iniciais des- 
sas partículas que escaparam estão localizadas no meio do intervalo original. Então restam dois intervalos de mesmo tamanho cujas trajetórias permanecem na região de espalhamento por um tempo mínimo $2 T_{0}$. No tempo $3 T_{0}$, uma outra fração $\eta$ das partículas remanescentes no tempo $2 T_{0}$ escapam. Assumindo que essas partículas pertenciam à parte central dos dois intervalos existentes, restam agora quatro intervalos. Esse processo é ilustrado na Fig. 4.1. Seguindo essa construção, no $n$-ésimo estágio obtemos $2^{n}$ intervalos cujocomprimento é $\frac{(1-\eta)^{n}}{2^{n}} \epsilon_{0}$. A dimensão capacidade é definida por

$$
d_{\text {cap }}=-\lim _{\epsilon \rightarrow 0} \frac{\ln N_{\epsilon}}{\ln \epsilon}
$$

onde $N_{\epsilon}$ é o número de cubos de tamanho $\epsilon$ necessários para cobrir o intervalo. Para o conjunto de Cantor construído na Fig. 4.1 a dimensão capacidade é dada por

$$
d_{\text {cap }}=-\lim _{\epsilon \rightarrow 0} \frac{\ln N_{\epsilon}}{\ln \epsilon}=-\lim _{n \rightarrow \infty} \frac{\ln 2^{n}}{\ln \left(\frac{1-\eta}{2}\right)^{n}},
$$

de modo que

$$
d_{\text {cap }}=\frac{\ln 2}{\ln \left(\frac{1-\eta}{2}\right)^{-1}} .
$$

Nesse caso, o decaimento das partículas na região de espalhamento é da forma $N(t)=$ $N_{0} \exp (-\gamma t)$ [4]. Assim, $N\left(t+T_{0}\right)=N_{0} \exp \left(-\gamma\left(t+T_{0}\right)\right)$. Pelo raciocínio utilizado na construção do conjunto, temos também que $N\left(t+T_{0}\right)=(1-\eta) N(t)=(1-\eta) N_{0} \exp (-\gamma t)$. Daí temos que a taxa de decaimento é constante e igual a $\gamma=T_{0}^{-1} \ln (1-\eta)^{-1}$.

Quando consideramos o caso não-hiperbólico, o decaimento das partículas na região de espalhamento é da forma $N(t)=N_{0} t^{-\alpha}$ e a taxa de decaimento $\eta_{n}$ não é constante, diminuindo conforme $n$ aumenta. A variação no decaimento das partículas é dada por

$$
\frac{d N(t)}{d t}=-\frac{\alpha N(t)}{t}=-\frac{\alpha N(t)}{n T_{0}}
$$

Mas, pela definição de derivada, também temos que

$$
\frac{d N(t)}{d t}=\lim _{T_{0} \rightarrow 0} \frac{N\left(t+T_{0}\right)-N(t)}{T_{0}} .
$$

Igualando essas duas expressões tiramos que

$$
N\left(t+T_{0}\right)-N(t)=-\frac{\alpha}{n} N(t)
$$


$n$

0

1

2

$n$
$N$

1

2

$4 \quad \epsilon_{2}=\frac{1}{2^{2}}(1-\eta)^{2}$

$2^{n}$ $\epsilon$

$$
\epsilon_{0}=1
$$

$$
\epsilon_{1}=\frac{1}{2}(1-\eta)
$$$$
\epsilon_{2}=\frac{1}{2^{2}}(1-\eta)^{2}
$$

$\epsilon_{n}=\frac{1}{2^{n}}(1-\eta)^{n}$

Figura 4.1: Construção de um conjunto de Cantor de dimensão 1.

que leva à

$$
\eta_{n} \approx \frac{\alpha}{n}
$$

Substituindo (4.4) em (4.3), chegamos à

$$
d_{c a p}=\frac{\ln 2}{\ln \left(\frac{1-\eta}{2}\right)^{-1}}=-\frac{\ln 2}{\ln \left(1-\eta_{n}\right)-\ln 2} .
$$

No limite de $n \rightarrow \infty$,

$$
d=\lim _{n \rightarrow \infty}\left[-\frac{\ln 2}{\ln \left(1-\frac{\alpha}{n}\right)-\ln 2}\right]=1 .
$$

Chegamos então a um conjunto de Cantor de dimensão 1 através de um argumento heurístico que leva à conjectura de que a dimensão pode ser 1 no caso do espalhamento não-hiperbólico [4].

Neste capítulo, estudamos um mapa quadrático que preserva a área [17-19]. Este mapa apresenta espalhamento hiperbólico ou não-hiperbólico, de acordo com o parâmetro real $\lambda$,

$$
\begin{aligned}
& x_{i+1}=\lambda\left(x_{i}-\frac{\left(x_{i}+y_{i}\right)^{2}}{4}\right), \\
& y_{i+1}=\frac{1}{\lambda}\left(y_{i}+\frac{\left(x_{i}+y_{i}\right)^{2}}{4}\right) .
\end{aligned}
$$


Para valores $\lambda \lesssim 6,5$, o mapa é não-hiperbólico [4]. A dinâmica é aberta, com trajetórias vindas do infinito e espalhadas em direção ao infinito novamente depois de um tempo de interação. A Fig. 4.2 mostra o espaço de fase para diferentes valores de $\lambda$. Para os valores $\lambda=2,0$ e $\lambda=3,0$, o mapa é não-hiperbólico e possui ilhas KAM no espaço de fase. Com $\lambda=5,0$, a estrutura de ilhas quase desaparece. Em $\lambda=7,0$ não existem mais ilhas KAM. Para a Fig. 4.2, iteramos por 1000 vezes 102400 condições iniciais distribuídas uniformemente em $-20 \leq x \leq 20$ e $-20 \leq y \leq 20$.

(a) $\lambda=2,0$

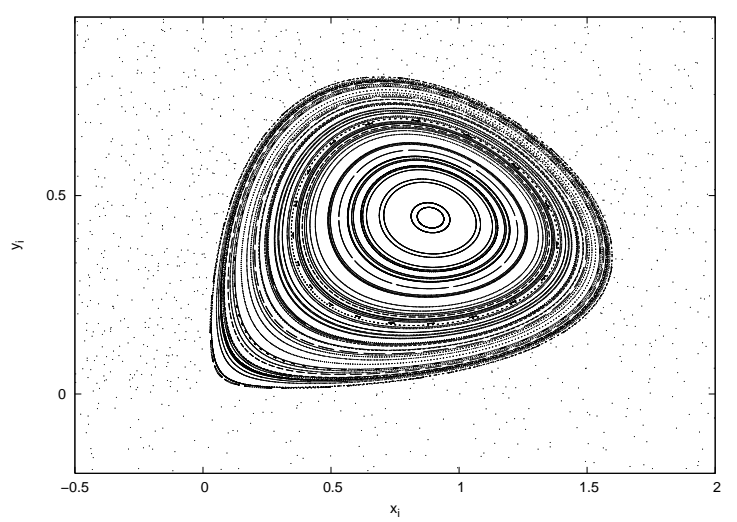

(c) $\lambda=5,0$

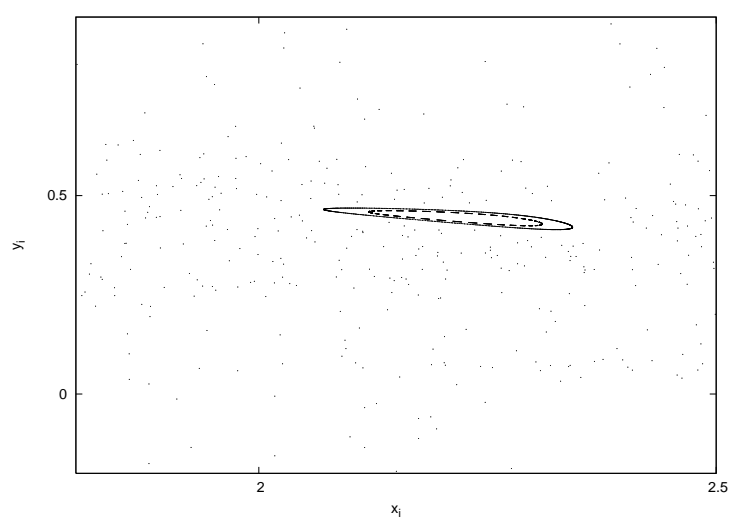

(b) $\lambda=3,0$

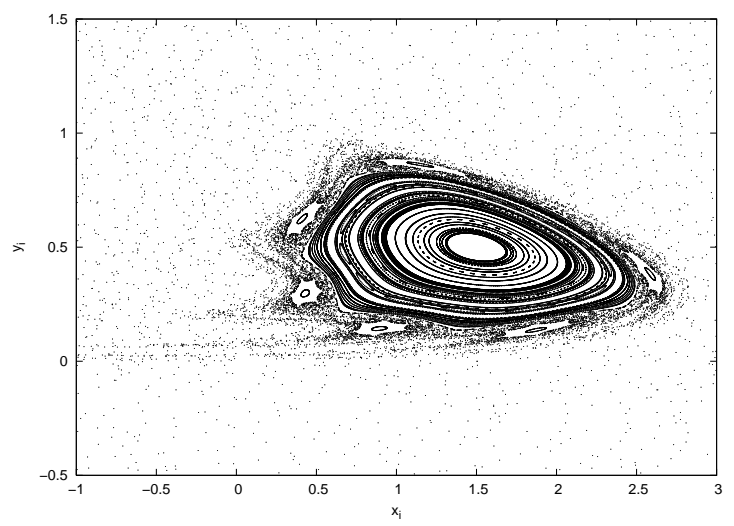

(d) $\lambda=7,0$

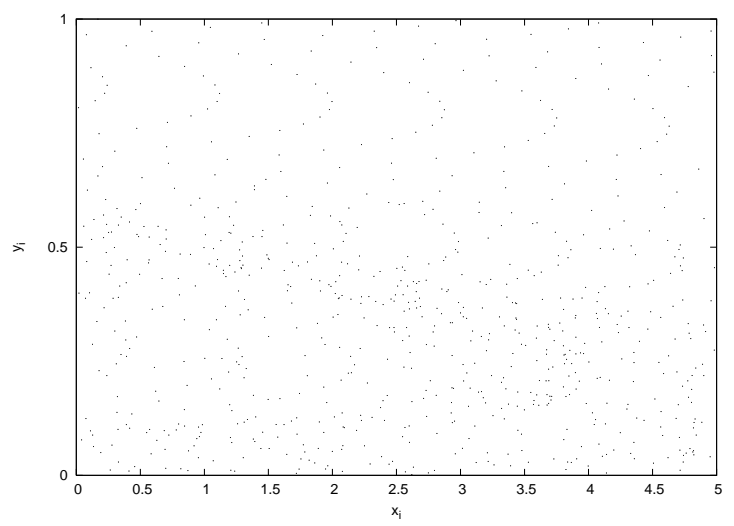

Figura 4.2: Espaço de fase para diferentes valores de $\lambda$. Nas Figs. (a), (b) e (c), o mapa é nãohiperbólico.

A fim de evitar as partículas presas nas ilhas de movimento regular, usamos a função de espalhamento $T \times x_{0}$ para selecionar intervalos onde as partículas possuam tempo de escape $T$ finito e assim garantimos que todas as partículas consideradas no cálculo do tempo de decaimento escaparão da região de espalhamento em algum tempo $t$. Na Fig. 4.3 mostramos a função de espalhamento para o caso não-hiperbólico (Figs. 4.3 (a), (b) e (c)) e para o caso hiperbólico (Fig. 4.3 (d)). Em (a) usamos $10^{4}$ condições iniciais tomadas em 
$0,06 \leq x \leq 0,09$ e em (b) $10^{4}$ condições iniciais tomadas em $0,075 \leq x \leq 0,085$, sendo $y=-0,2$ e $\lambda=3,0$ para (a) e (b). Para a situação em que o espalhamento é hiperbólico, $10^{4}$ condições iniciais foram tomadas em $-1 \leq x \leq 4$ em (c) e $10^{4}$ condições iniciais foram tomadas em $0,15 \leq x \leq 0,70$ em (d), com $y=0,5$ e $\lambda=8,0$ para (c) e (d). Comparando a Fig. 4.3(a) com a Fig. 4.3(b) percebemos uma maior densidade de singularidades na ampliação mostrada em (b), do que em (a). Isto é qualitativamente diferente do caso hiperbólico, onde a ampliação (d) não se distingue da escala maior (c).

(a)

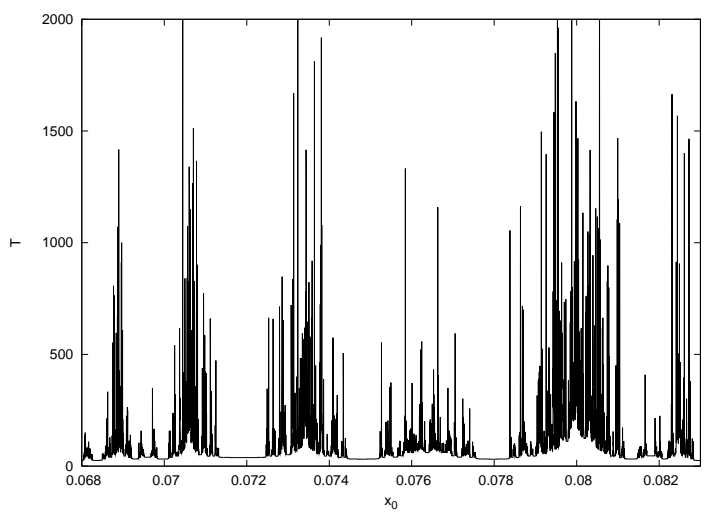

(c)

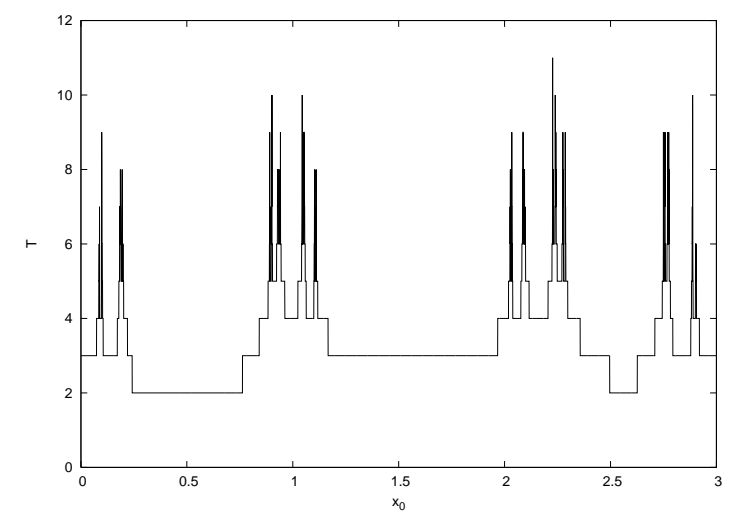

(b)

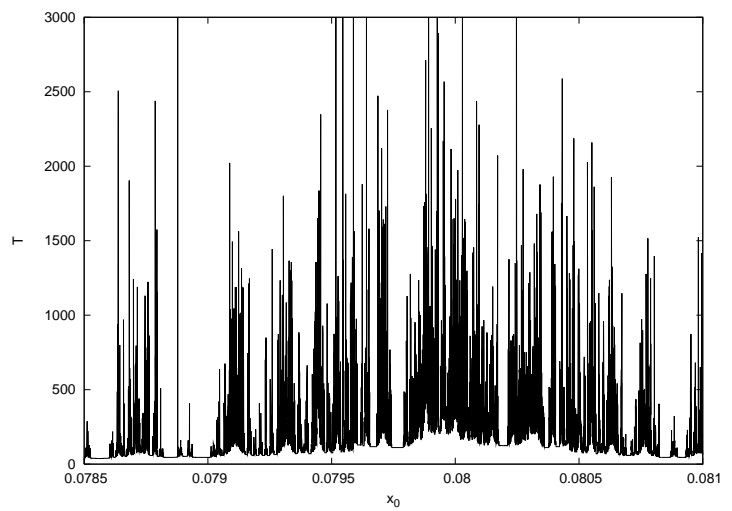

(d)

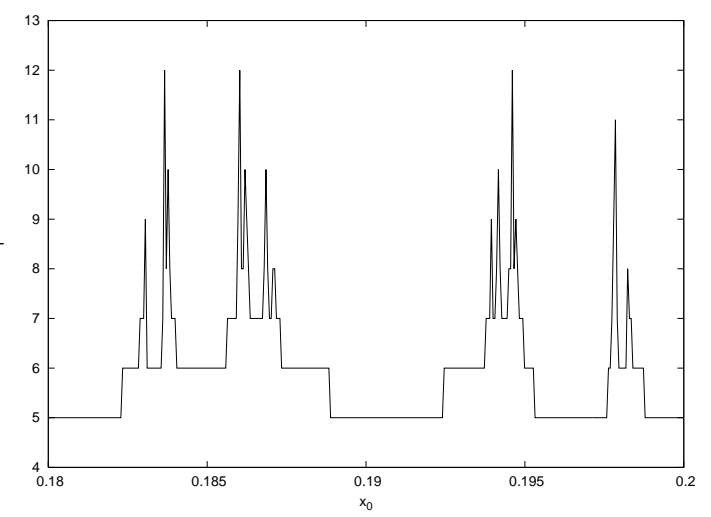

Figura 4.3: Função de espalhamento para $\lambda=3,0$, (a) e (b), e $\lambda=8,0$, (c) e (d). Usamos as seguintes condições iniciais: (a) $10^{4}$ partículas com $y=-0,2,0,06 \leq x \leq 0,09, \lambda=3,0$; (b) $10^{4}$ partículas com $y=-0,2,0,075 \leq x \leq 0,085, \lambda=3,0$; (c) $10^{4}$ partículas com $y=0,5,-1 \leq x \leq 4$, $\lambda=8,0$; (d) $10^{4}$ partículas com $y=0,5,0,15 \leq x \leq 0,70, \lambda=8,0$. No caso hiperbólico, a escala de observação não interfere na função de espalhamento, tornando as figuras (c) e (d) indistinguíveis. Para o caso não-hiperbólico, a ampliação (b) de (a) possui uma densidade maior de singularidades.

Tomamos um pequeno intervalo em torno de um $x_{0}$, onde o tempo de escape é finito e calculamos a dimensão do conjunto pelo método da fração incerta [3]. O método da fração incerta foi utilizado na Sec. 3.1, quando calculamos a dimensão da bacia de atração para o potencial espalhador dado pela Eq. (3.1). Lembramos que $f$ é a fração incerta e $\varepsilon$ 


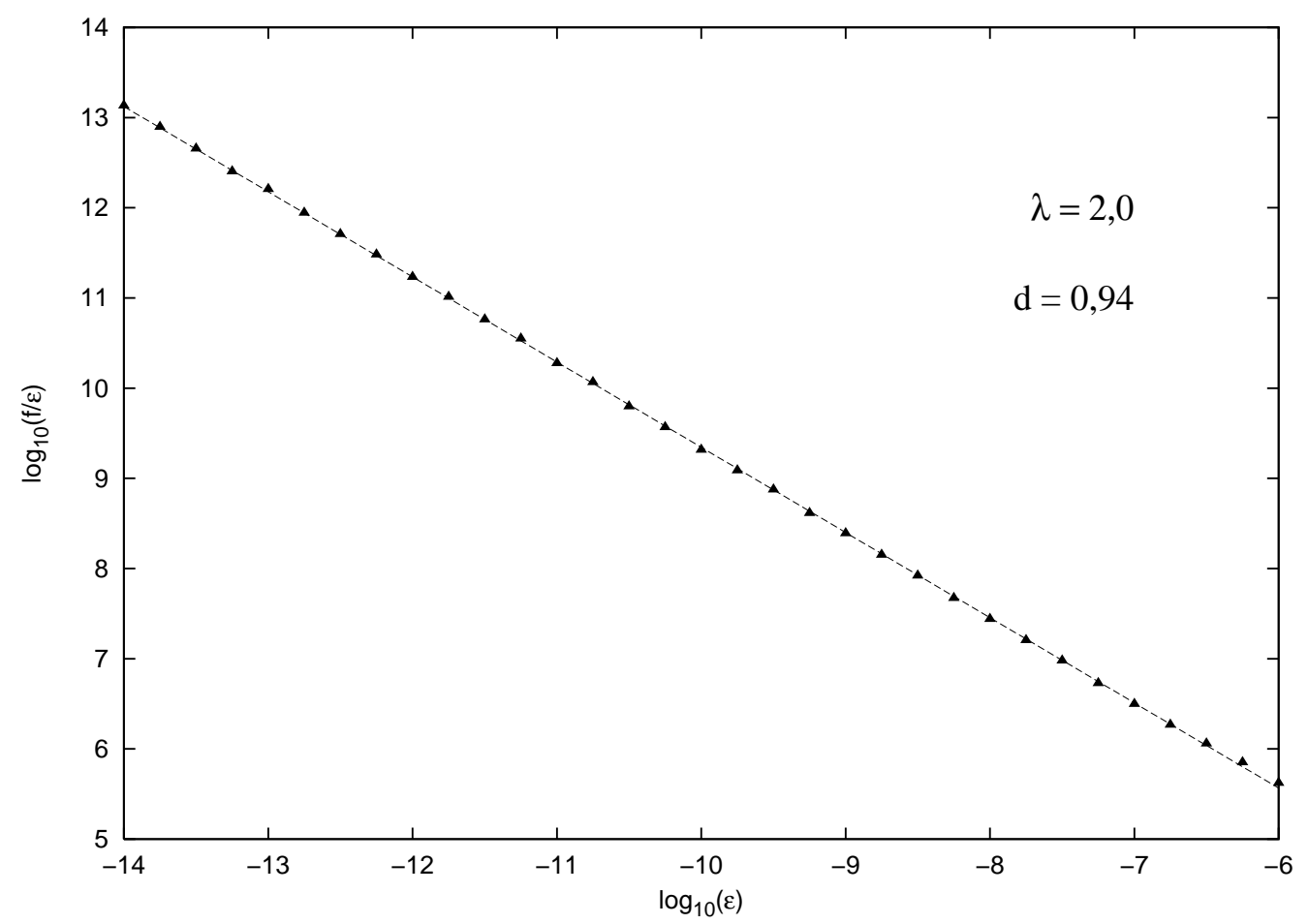

Figura 4.4: Gráfico de $\log _{10}(f / \varepsilon) \times \log _{10}(\varepsilon)$ quando $\lambda=2,0$, onde $f$ é a fração incerta e $\varepsilon$ é a incerteza. A inclinação da reta é a dimensão $d=0,94$ para $y_{0}=-0,15$ no intervalo $\left[x_{0}, x_{0}+\delta_{x}\right]$, com $x_{0}=0,005920$ e $\delta_{x}=10^{-5}$.

é a incerteza na condição inicial, e ainda $f(\varepsilon) \sim \varepsilon^{(1-d)}$, onde $d$ é a dimensão do conjunto. Assim, no gráfico $\log _{10}(f / \varepsilon) \times \log _{10}(\varepsilon)$ da Fig. 4.4, a inclinação da reta fornece a dimensão $d$, na situação em que $\lambda=2,0$, quando o mapa apresenta comportamento não-hiperbólico. Para o intervalo em $y=-0,15$ com $\left[x_{0}, x_{0}+\delta_{x}\right]$, com $x_{0}=0,005920$ e $\delta_{x}=10^{-5}$, a dimensão é $d=0,94$.

Evoluímos as condições da Fig. 4.3(a) sob o mapa (4.6) e consideramos a região de espalhamento como o quadrado centrado na origem e delimitado por $|x| \leq 5$ e $|y| \leq 5$, mostrado na Fig. 4.5.

Dentre as condições iniciais que possuem tempos de escape finitos, estamos interessados naquelas cujos tempos necessários para o escape sejam os maiores. Isto equivale a tomar as partículas que interceptam a variedade estável da sela caótica. Para condições que satisfazem esse critério, calculamos o número de partículas que permanecem na região de espalhamento da Fig. 4.5 em cada iteração.

$\mathrm{Na}$ Fig. 4.6 temos o gráfico $\log$ - log do número de partículas na região de escape, $N(t)$, pelo tempo discreto $t$. O decaimento das partículas é bastante lento devido ao efeito de aprisionamento - trapping — das ilhas KAM. Esse decaimento é regido por uma lei de potência [4], $N(t) \sim t^{\gamma}$ para tempos longos, como podemos ver na Fig. 4.6. As condições 


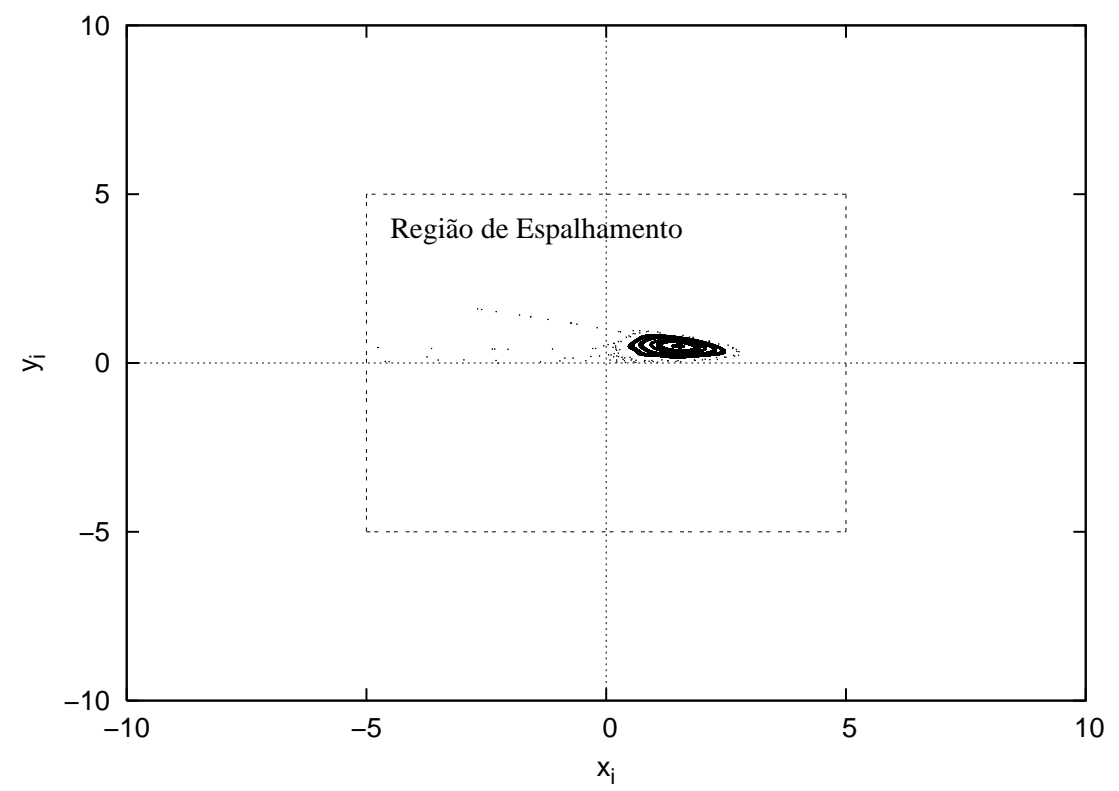

Figura 4.5: Região de espalhamento para $\lambda=3,0$. Consideramos as partículas que estão fora dessa região como partículas que escaparam.

iniciais foram escolhidas de forma que todas as partículas escapem para algum tempo, que pode ser arbitrariamente longo. Para a Fig. 4.6, começamos com $10^{9}$ partículas ao longo da linha de condições iniciais com $y=-0,2$ e $0 \leq x \leq 0,02$. Iteramos o mapa até que

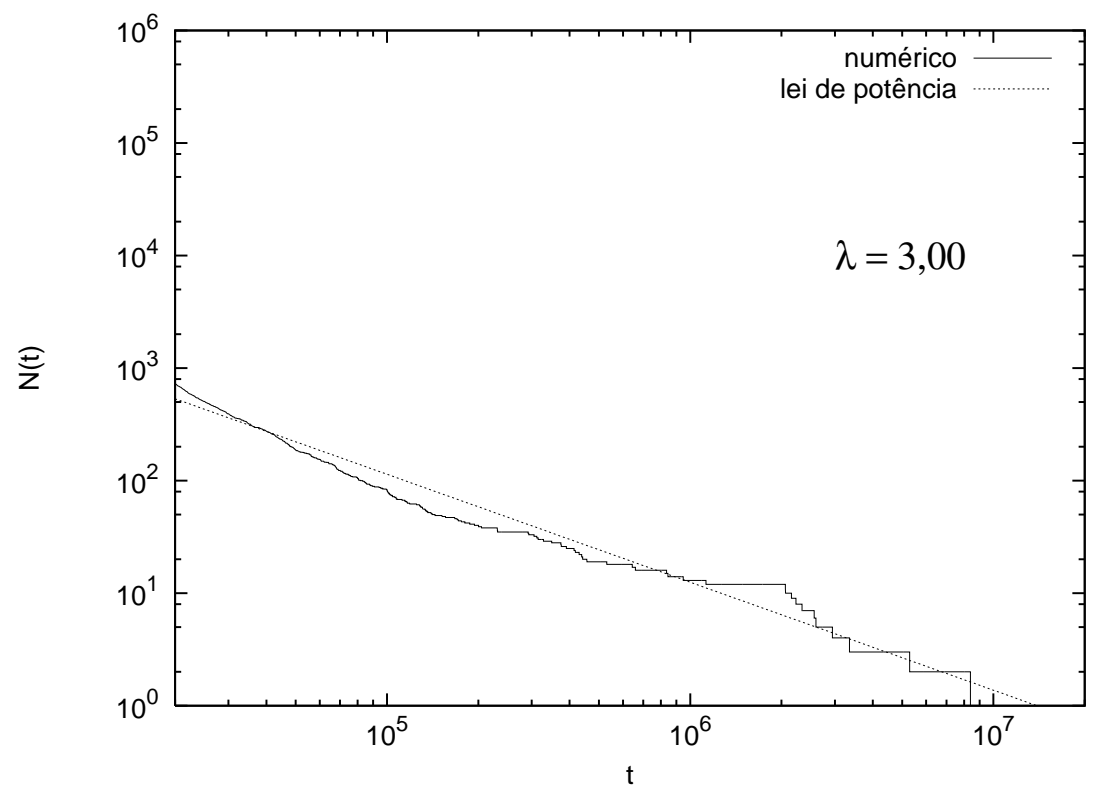

Figura 4.6: Gráfico $\log -\log$ do número de partículas na região de escape, $N(t)$, pelo tempo discreto t. Começamos com $10^{9}$ partículas ao longo da linha de condições iniciais com $y=-0,2$ e $0 \leq x \leq$ 0, 02. Foram necessárias 19145600 iterações até que todas as partículas tivessem escapado da região apresentada na Fig. 4.5. 
todas as partículas tivessem escapado, o que aconteceu depois de 19145600 iterações. A lei de potência ajustada aos dados obtidos é do tipo $N(t)=A t^{-\gamma}, \operatorname{com} A=7,1307 \times 10^{6} \mathrm{e}$ $\gamma=0,95933$.

Calculamos o mapa para uma grade de $5000 \times 5000$ pontos distribuídos uniformemente em $0 \leq x \leq 0,05$ e $-0,2 \leq y \leq-0,1$, a fim de encontrar as condições iniciais que permanecem mais tempo na região de espalhamento, quando $\lambda=3,0$. Dessa forma, encontramos as condições iniciais que interceptam a variedade estável do conjunto invariante. O resultado está na Fig. 4.7.

Apresentadas as duas características mais importantes do espalhamento caótico nãohiperbólico, passamos agora a estudar as implicações de uma perturbação randômica no parâmetro $\lambda$.

\subsection{Espalhamento Caótico Não-Hiperbólico com Perturbações Randômicas}

No Cap. 2 mostramos como perturbações randômicas são aplicadas a diferentes mapas e que a escolha de snapshots é adequada ao estudo, no sentido que revela as estruturas fractais de atratores e selas caóticas.

Aplicamos uma perturbação randômica no parâmetro $\lambda$ do mapa (4.6), de modo que $\lambda$ seja dado por

$$
\lambda_{i}=\lambda+\Delta_{\lambda} r
$$

semelhantemente aos parâmetros randômicos do trabalho de Romeiras et al [5]. As quantidades $\lambda$ e $\Delta_{\lambda}$ são fixas e $r$ é uma variável randômica cujo valor está compreendido entre 0 e 1. Na Fig. 4.8 temos o número de iterações versus o parâmetro $\lambda$, quando a amplitude de perturbação $\Delta_{\lambda}$ é igual à 0,18 . Como esperávamos, a distribuição dos valores do parâmetro é aproximadamente uniforme.

Como na Fig. 4.3, plotamos a função de espalhamento $T \times x_{0}$, quando $\lambda=3,0$ e agora $\Delta_{\lambda}=0,18$, para $10^{4}$ condições iniciais tomadas em $y=-0,2,0,16 \leq x \leq 0,22 \mathrm{em}$ Fig. 4.9(a) e $0,174 \leq x \leq 0,177$ em Fig. 4.9(b) e $10^{5}$ iterações. A perturbação randômica aplicada ao parâmetro não provoca mudanças qualitativas perceptíveis na função de espalhamento.

Diferentemente da situação em que o mapa não é randômico e existe um conjunto invariante formado pela interseção das variedades estáveis e instáveis, no caso do mapa randômico não existe um conjunto invariante, pois para que um dado conjunto $E$ seja inva- 
riante por uma aplicação $M$ devemos ter $M(E)=E$. Jacobs et al. [7] definem para esses casos conjuntos análogos ao conjunto invariante e suas variedades estáveis e instáveis, recebendo a denominação de entrainment, pre-entrainment e intermediate para um determinado tempo de observação, constituídos por seqüências aninhadas de conjuntos que numa situação típica aproximam-se de conjuntos fractais de medida nula no limite de um tempo infinito. Esses conjuntos não são invariantes porque movem-se irregularmente com o aumento do tempo [7]. Assim, o que vemos na Fig. 4.10 é um conjunto análogo à variedade estável de um conjunto invariante. Temos na Fig. 4.10(a) as mesmas condições iniciais da Fig. 4.7(a), porém com $\Delta_{\lambda}=0,18$. As Figs. 4.10(b) e (c) são ampliações das regiões destacadas em (a) e (b), respectivamente.

Na Fig. 4.9, plotamos a função de espalhamento no caso em que perturbamos randomicamente o parâmetro, quando ele apresenta não-hiperbolicidade. As condições iniciais foram tomadas em $y=-0,2,0,16 \leq x \leq 0,22$ em (a) e $0,174 \leq x \leq 0,177$ em (b). Para ambas as figuras iteramos $10^{5}$ vezes o número de $10^{4}$ condições iniciais. Comparando a Fig. 4.9 com a Fig. 4.3, vemos que a presença de randomicidade não provoca mudanças qualitativas perceptíveis na função de espalhamento.

\subsubsection{Tempo de Decaimento}

Como já apresentamos no início deste capítulo, o tempo de decaimento das partículas na região de espalhamento é regido por uma lei de potência no caso do espalhamento nãohiperbólico. O que observamos na lei de decaimento sob as perturbações randômicas está na Fig. 4.11. O gráfico log-linear mostra que a lei de potência que inicialmente ajustava o decaimento das partículas não está de acordo com os dados. Entretanto, um decaimento exponencial do tipo $N(t)=B e^{-\beta t}$, se ajusta muito bem ao caso. Inicialmente eram necessárias $10^{7}$ iterações para que todas as partículas estivessem fora da região de espalhamento, ao passo que agora com $10^{4}$ iterações todas as partículas escaparam, lembrando que em nenhuma situação trabalhamos com as partículas presas em regiões de movimento regular.

$\mathrm{Na}$ Fig. 4.12, tomamos diferentes valores para a amplitude de perturbação $\Delta_{\lambda}$ e obtivemos o melhor ajuste por um decaimento exponencial, encontrando assim a taxa de decaimento $\beta$. O gráfico de $\beta \times \Delta_{\lambda}$ mostra uma aparente dependência quadrática de $\beta$ em relação à $\Delta_{\lambda}$. Assim a figura sugere que temos $\beta=C\left(\Delta_{\lambda}\right)^{2}$, onde $C$ é uma constante. 
(a)

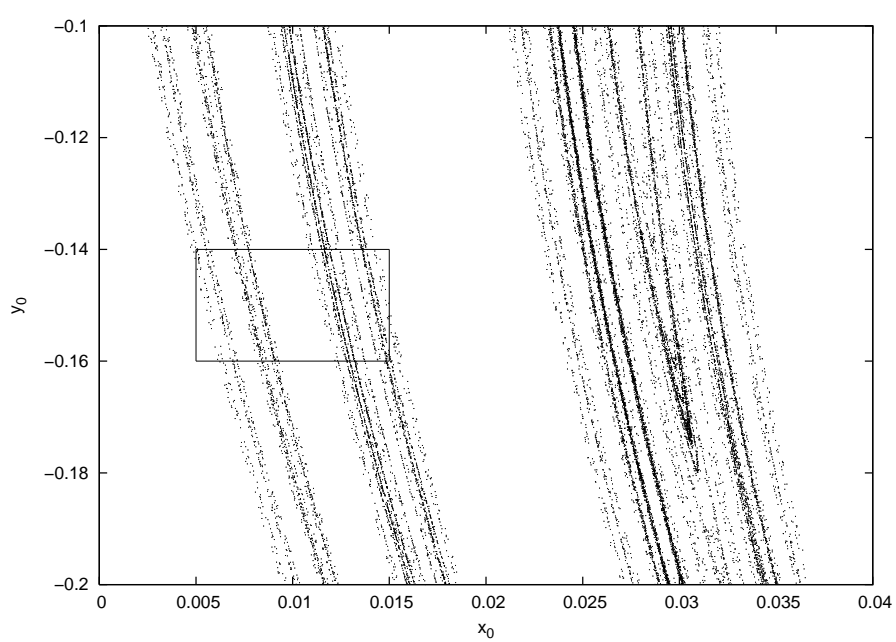

(b)

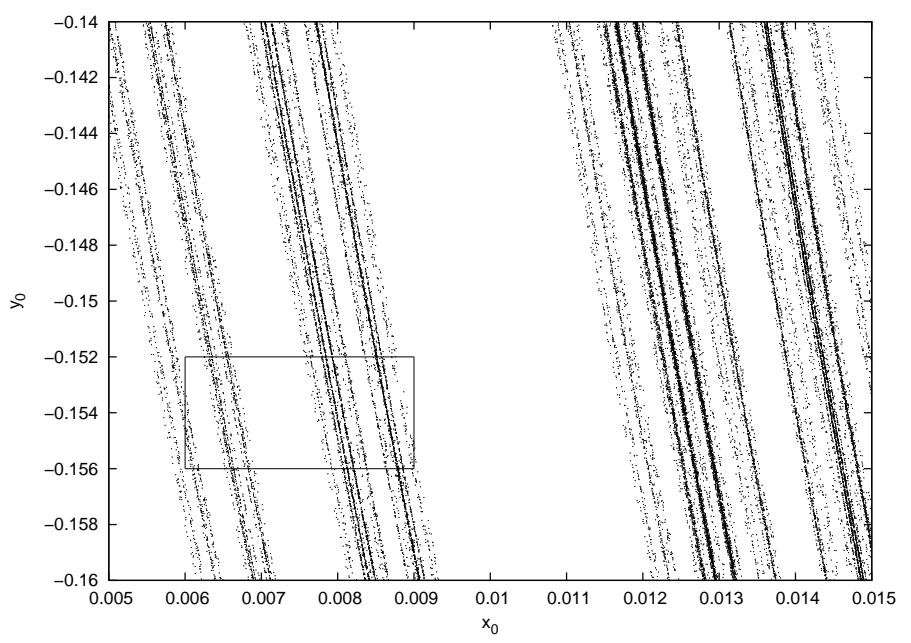

(c)

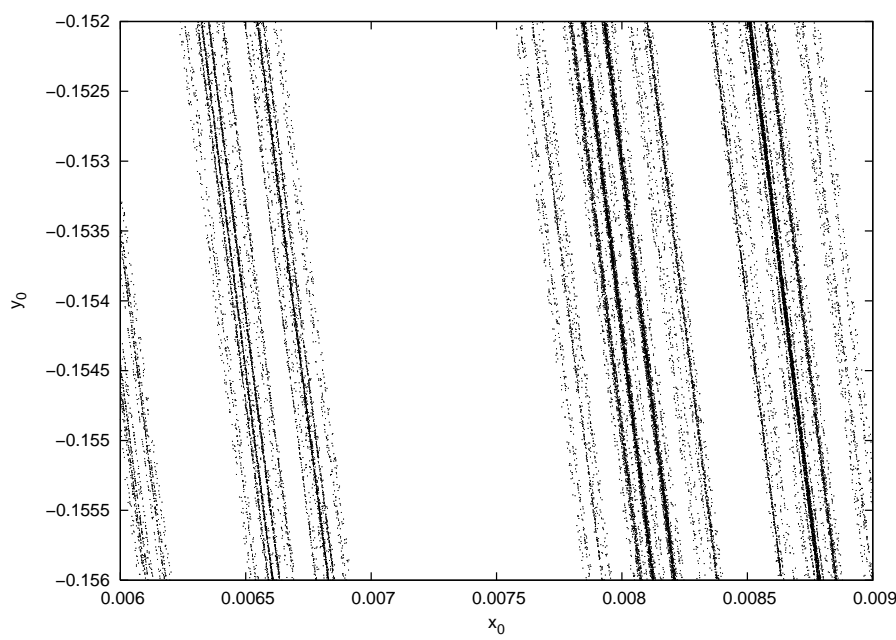

Figura 4.7: Condições iniciais que possuem os maiores tempos de escape. Tomamos $5000 \times 5000$ pontos distribuídos uniformemente em (a) $0 \leq x \leq 0,05 \mathrm{e}-0,2 \leq y \leq-0,1$ quando $\lambda=3$, 0 . As Figs. (b) e (c) são ampliações sucessivas das regiões indicadas em (a) e (b), respectivamente. 


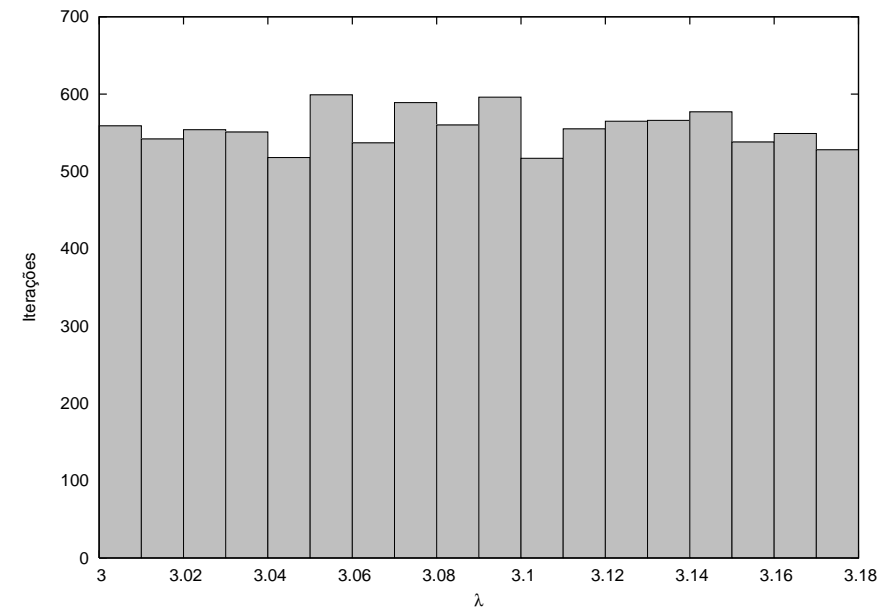

Figura 4.8: Histograma dos valores de $\lambda$. Para $\Delta_{\lambda}=0,18$, e para $10^{4}$ iterações e obtivemos uma distribuição aproximadamente uniforme dos valores de $\lambda$.

(a)

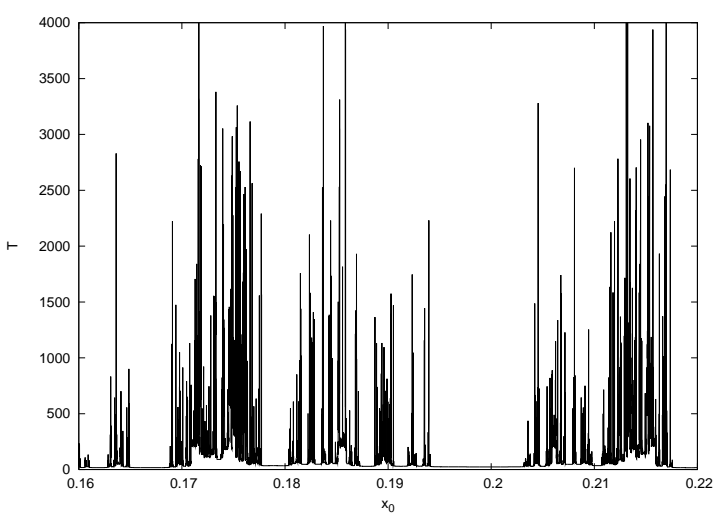

(b)

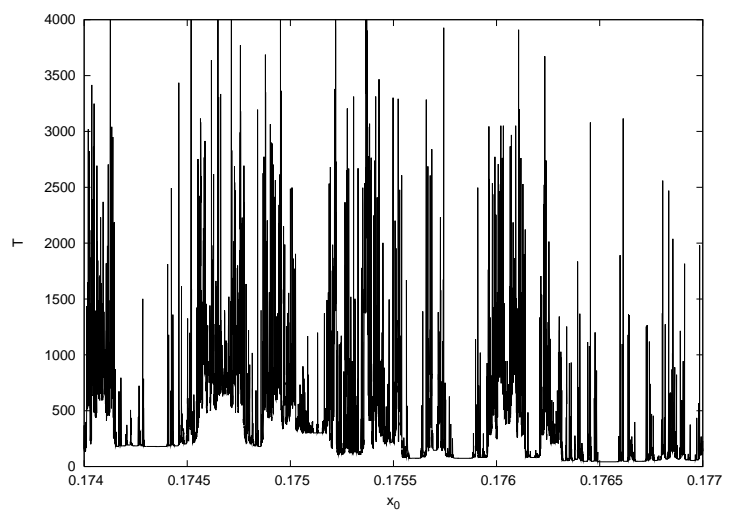

Figura 4.9: Função de espalhamento para $\lambda=3,0, \Delta_{\lambda}=0,18 \mathrm{em}$ (a) e (b). As condições iniciais foram tomadas em $y=-0,2,0,16 \leq x \leq 0,22 \mathrm{em}$ (a) e $0,174 \leq x \leq 0,177 \mathrm{em}$ (b). Para ambas as figuras iteramos $10^{5}$ vezes o número de $10^{4}$ condições iniciais. A presença de randomicidade não provoca mudanças qualitativas perceptíveis na função de espalhamento (ver Fig. 4.3). 
(a)

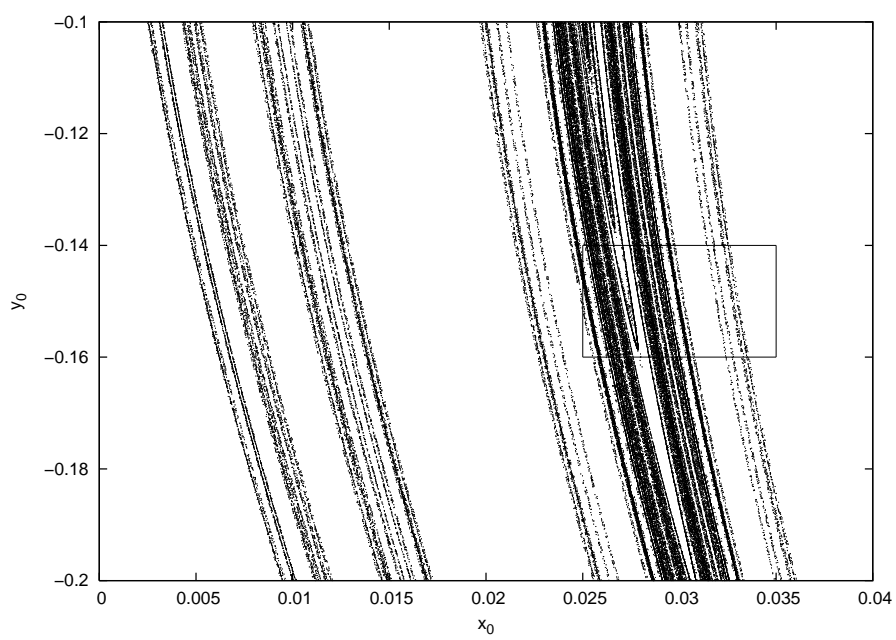

(b)

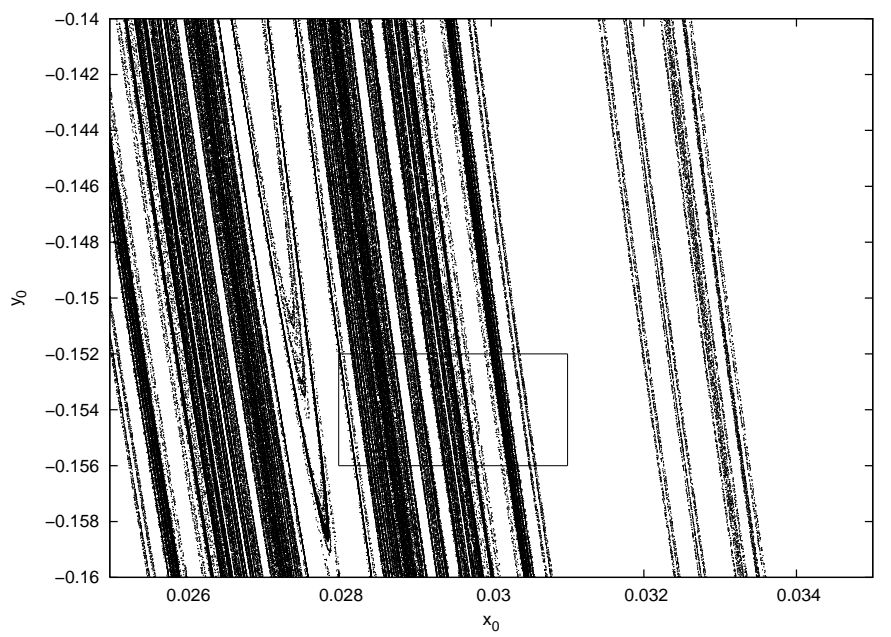

(c)

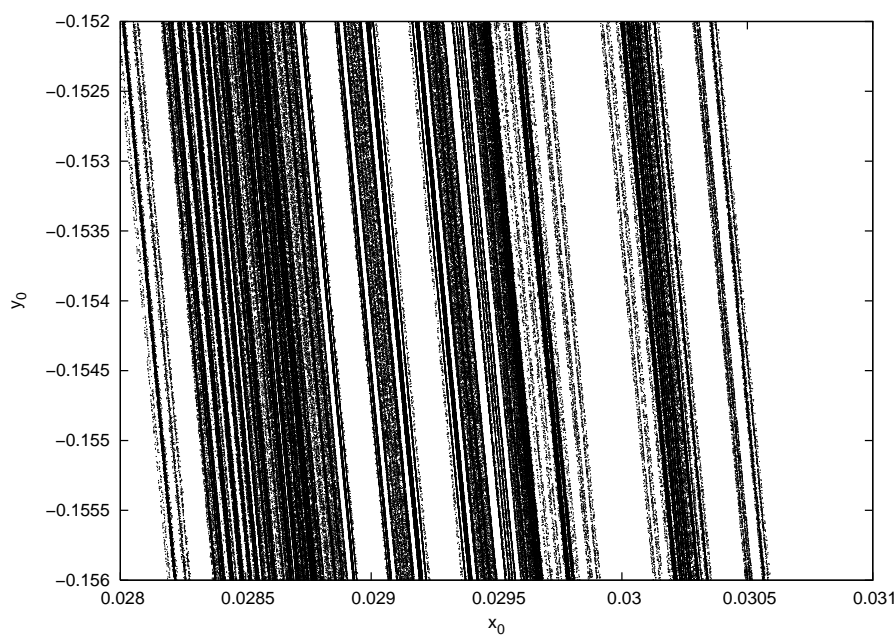

Figura 4.10: Condições iniciais que possuem os maiores tempos de escape, agora quando o parâmetro $\lambda$ varia randomicamente. Tomamos $5000 \times 5000$ pontos distribuídos uniformemente em (a) $0 \leq x \leq 0,05$ e $-0,2 \leq y \leq-0,1$. As Figs. (b) e (c) são ampliações sucessivas das regiões indicadas em (a) e (b), respectivamente. 


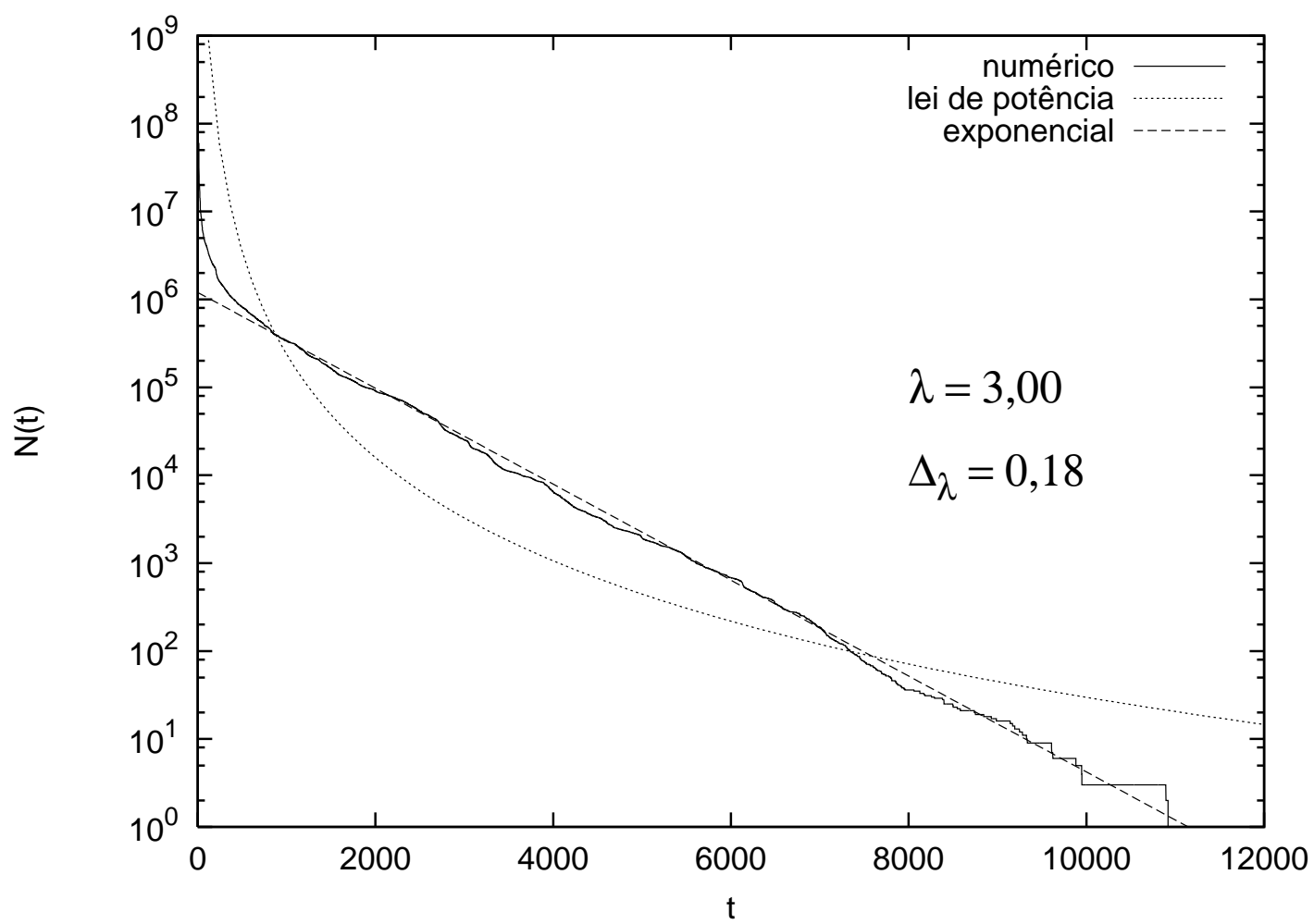

Figura 4.11: Gráfico $\log$-linear do número de partículas na região de escape, $N(t)$, pelo tempo discreto $t$. Como na Fig. 4.6, começamos com $10^{9}$ partículas ao longo da linha de condições iniciais com $y=-0,2$ e $0 \leq x \leq 0,02$. Com o parâmetro $\lambda$ randômico, observamos a mudança da lei de decaimento das partículas na região de espalhamento, que passa a ser da forma exponencial, $N(t) \sim \exp (-\beta t)$. 


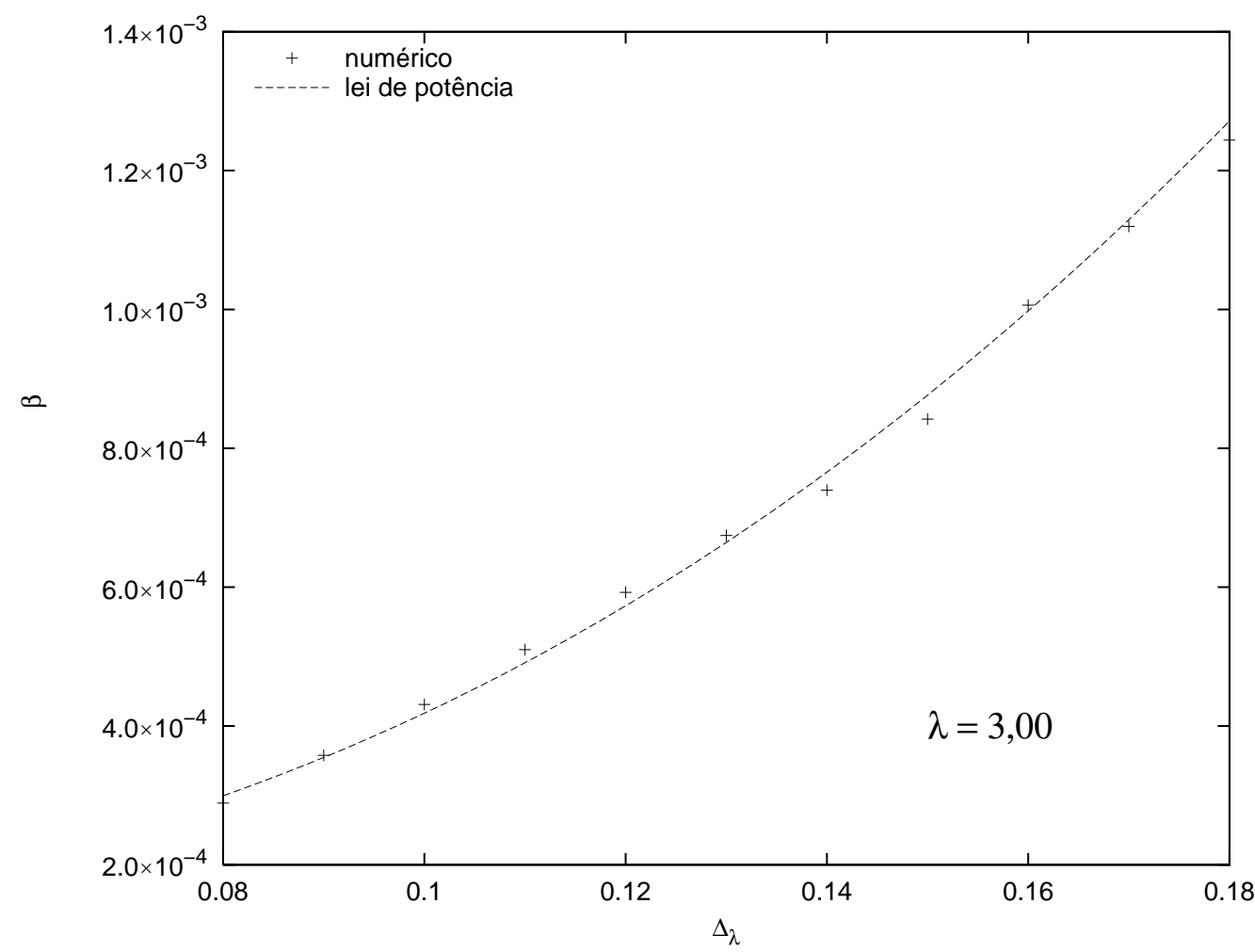

Figura 4.12: Variamos a perturbação randômica aplicada ao parâmetro $\lambda$ através da variação de $\Delta_{\lambda}$ e, para cada $\Delta_{\lambda}$, encontramos a taxa de decaimento $\beta$ que melhor ajusta a curva $N(t) \sim \exp (-\beta t)$. O melhor ajuste que encontramos para os valores numéricos é uma função quadrática. 


\section{Capítulo 5}

\section{Discussão}

O espalhamento caótico não-hiperbólico possui características bem definidas em relação à dimensão fractal, à função de espalhamento e à lei de decaimento das partículas. No Cap. 4 apresentamos os gráficos que demonstram essas características para as situações de espalhamento não-hiperbólico com e sem aplicação de perturbações randômicas no parâmetro $\lambda$. Procuramos utilizar as mesmas condições iniciais, quando foi possível, a fim de comparar melhor os resultados. No decorrer do trabalho, pareceu razoável admitir $\Delta_{\lambda}=0,18$ como a maior perturbação a ser aplicada, pois seus efeitos poderiam ser observados e ainda a perturbação pôde ser considerada como pequena. O valor mínimo $\Delta_{\lambda}=0,08$ foi imposto pela precisão dos cálculos. O cálculo para perturbações próximas de zero exige computações muito lentas, devido ao longo transiente quando $\varepsilon \rightarrow 0$ e, por outro lado, encontra rapidamente problemas numéricos, como a periodicidade induzida por arredondamento [20].

Primeiramente, vimos que no caso não-hiperbólico a função de espalhamento é singular sobre um conjunto de Cantor de condições iniciais e, diferentemente do caso hiperbólico, esse conjunto tem uma dimensão efetiva aproximadamente igual a 1. Comprovamos isso pelo cálculo numérico da dimensão fractal, para um valor do parâmetro em que o mapa é não-hiperbólico. Porém, não foi possível calcular até então a dimensão no caso do espalhamento sob perturbações randômicas, pois todos os valores para a dimensão divergiam.

A análise qualitativa da função de espalhamento no caso não-hiperbólico com perturbações randômicas não revela qualquer modificação da dinâmica, de modo que é impossível distinguir a situação em que existem as perturbações randômicas da situação onde o parâmetro $\lambda$ não varia com o tempo. As ampliações de determinadas regiões da função de espalhamento também apresentaram uma maior densidade de picos, como acontece no caso não-hiperbólico sem perturbações. Assim, apenas com base na função de espalhamento não podemos fazer nenhuma afirmação sobre as mudanças introduzidas pela perturbação 
randômica.

Para a situação de espalhamento não-hiperbólico, construímos o gráfico da variedade estável plotando as condições iniciais das órbitas que levavam mais tempo para escapar da região de espalhamento. Para o caso randômico, o conjunto não é invariante, no sentido estrito da palavra, mas constitui um conjunto análogo, chamado de pre-entrainment por Jacobs et al. [7]. Quando tomamos a variedade estável e a comparamos com seu análogo para o caso randômico, percebemos um aumento na densidade de pontos. Numa primeira avaliação poderíamos pensar que a presença de randomicidade aumenta o número de condições iniciais que permanecem por mais tempo na região de espalhamento. Mas tal situação é contraditória, pois, como vimos na Subsec. 4.1.1, na presença de randomicidade o tempo exigido para as partículas escaparem da região de espalhamento é menor do que na ausência de randomicidade. Para entender esse processo, vejamos o que ocorre com o decaimento das partículas.

O decaimento das partículas na região de espalhamento segue uma lei de potência no caso não-hiperbólico e uma exponencial para o caso hiperbólico. A perturbação randômica aplicada a $\lambda$ modifica substancialmente o decaimento das partículas quando o espalhamento é não-hiperbólico. O decaimento (originalmente na forma de lei de potência), passa a ser do tipo exponencial, mesmo para valores de $\Delta_{\lambda}$ menores que 0,08 , sendo complicado nessas situações encontrar a taxa de decaimento, como já falamos no início desse capítulo. Essa mudança estrondosa no decaimento das partículas sugere que a presença de perturbações randômicas impõe uma mudança drástica na dinâmica, com a perda da não-hiperbolicidade.

Em outras palavras, a mudança no decaimento das partículas é o indicativo mais forte de que as ilhas deixam de existir sob a introdução da randomicidade. A partir daqui, podemos explicar então o aumento do número de pontos que compõem o conjunto análogo à variedade estável. Uma vez que as ilhas foram destruídas, as órbitas que estavam confinadas nas regiões de movimento regular estão livres para interagir numa região maior no espaço de fase, antes de escapar para o infinito. Assim, o que observamos é a "migração" de órbitas que antes pertenciam às regiões de movimento regular e, que na condição randômica, não estão mais sujeitas aos limites impostos pelas ilhas KAM. Para um tempo infinitamente longo, todas as partículas sob perturbações randômicas escaparão da região de espalhamento.

Assumindo que ocorre a destruição total das ilhas quando a randomicidade é introduzida, algumas questões ficam em aberto. A primeira é a respeito da função de espalhamento, que não se altera com as perturbações randômicas e mantém as características não-hiperbólicas. A segunda compreende calcular a dimensão fractal no caso perturbado e completar o estudo do conjunto invariante, obtendo a variedade instável e a sela caótica na 
ausência de randomicidade e de seus análogos quando a perturbação é aplicada. Uma outra questão é a relação entre a taxa de decaimento das partículas perturbadas e a amplitude de perturbação, $\beta \times \Delta_{\lambda}$ : como fica essa relação para valores de $\Delta_{\lambda}$ próximos de zero?

Por fim, de forma análoga ao que foi feito para o problema do potencial composto por três picos no Cap. 3, delinear a transição da não-hiperbolicidade para a hiperbolicidade em duas situações distintas. A primeira situação é quando o mapa (4.6) apresenta uma transição natural de não-hiperbólico para hiperbólico para valores $\lambda \approx 6,5$. A segunda situação em que ocorre esta transição é quando aplicamos a perturbação randômica para valores abaixo de $\lambda \approx 6,5$. As respostas de todas essas perguntas são as perspectivas de continuação desse estudo sobre o espalhamento caótico não-hiperbólico com perturbações randômicas. 


\section{Referências Bibliográficas}

[1] A. E. Motter and Y.-C. Lai, "Dissipative chaotic scattering”, Phys. Rev. E 65, 015205 (2001).

[2] S. Bleher, C. Grebogi, and E. Ott, "Bifurcation to chaotic scattering", Physica D 46, 87 (1990).

[3] C. Grebogi, S. W. McDonald, E. Ott, and J. Yorke, "Final state sensitivity: an obstruction to predictability", Phys. Lett. A 99, 415 (1983).

[4] Y.-T. Lau, J. M. Finn, and E. Ott, "Fractal dimension in nonhyperbolic chaotic scattering", Phys. Rev. Lett. 66, 978 (1991).

[5] F. J. Romeiras, C. Grebogi, and E. Ott, "Multifractal properties of snapshot attractors of random maps", Phys. Rev. A 41, 784 (1990).

[6] A. Namenson, J. Thomas M. Antonsen, and E. Ott, "Power law wave number spectra of fractal particle distributions advected by flowing fluids", Phys. Fluids 8, 2426 (1996).

[7] J. Jacobs, E. Ott, T. Antonsen, and J. York, "Modeling fractal entrainment sets of tracers advected by chaotic temporally irregular fluid flows using random maps", Physica D 110, 1 (1997).

[8] M. Ding, C. Grebogi, E. Ott, and J. A. Yorke, "Transition to chaotic scattering”, Phys. Rev. A 42, 7025 (1990).

[9] M. Hénon, "A two-dimensional mapping with a strange attractor", Commun. Math. Phys. 50, 69 (1976).

[10] K. Ikeda, "Multiple-valued stationary state and its instability of the transmitted light by a ring cavity system", Opt. Commun. Phys. 30, 257 (1979). 
[11] K. Ikeda, H. Daido, and O. Akimoto, "Optical turbulence: chaotic behavior of transmitted light from a ring cavity", Phys. Rev. Lett. 45, 709 (1980).

[12] C. Grebogi, E. Ott, F. Romeiras, and J. A. Yorke, "Critical exponents for crisisinduced intermittency", Phys. Rev. A 36, 5365 (1987).

[13] L. Yu, E. Ott, and Q. Chen, "Fractal distribution of floaters on a fluid surface and the transition to chaos for random maps", Physica D 53, 102 (1991).

[14] S. W. McDonald, C. Grebogi, E. Ott, and J. A. Yorke, "Fractal basin boundaries", Phys. D 17, 125 (1984).

[15] K. T. Alligood, E. D. Yorke, and J. A. Yorke, "Why period-doubling cascades occur: Periodic orbit creation followed by stability shedding”, Phys. D 28, 197 (1987).

[16] S. Smale, "Differentiable dynamical systems", Bull. Amer. Math. Soc. 73 (1967).

[17] M. Hénon, "Numerical study of quadratic area-preserving mappings", Q. Appl. Math 23, 291 (1969).

[18] A. J. Dragt and J. M. Finn, "Lie series and invariant functions for analytic sympletic maps", J. Math. Phys. 17, 2215 (1976).

[19] A. P. S. Moura and C. Grebogi, "Reaction in flows with non-hyperbolic dynamics", Phys. Rev. E 70, 036216 (2004).

[20] C. Grebogi, E. Ott, and J. A. Yorke, "Roundoff-induced periodicity and the correlation dimension of chaotic attractos", Phys. Rev. A 38, 3688 (1988). 